\title{
SPEECH SOUND ACQUISITION IN A 5-YEAR-OLD SPANISH-ENGLISH BILINGUAL
}

CHILD

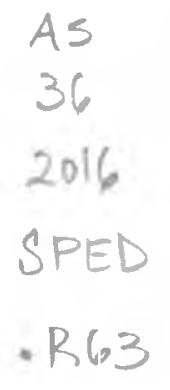

A thesis submitted to the faculty of

San Francisco State University

In partial fulfillment of

the requirements for

the Degree

Master of Science

In

Communicative Disorders

by

Jonathan Julius Deonn Robinson Anthony

San Francisco, California

Spring 2016 


\section{Copyright by}

Jonathan Julius Deonn Robinson Anthony 2016 


\section{CERTIFICATION OF APPROVAL}

I certify that I have read Spontaneous Speech of a Bilingual Spanish-English Child Organized by Phonological Complexity and the Relation to Parental Report of Language Proficiency and Exposure by Jonathan Julius Deonn Robinson Anthony, and that in my opinion this work meets the criteria for approving a thesis submitted in partial fulfillment of the requirement for the degree Master of Science in Communicative Disorders: Speech-Language Pathology at San Francisco State University.

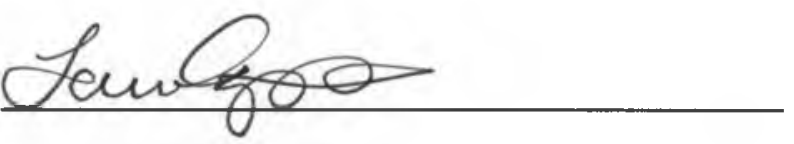

Laura Epstein, Ph.D.

Associate Professor of Communicative Disorders

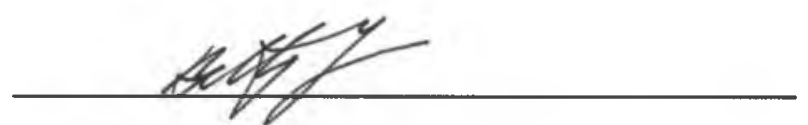

Betty Yu, Ph.D.

Associate Professor of Communicative Disorders 
SPEECH SOUND ACQUISITION IN A 5 YEAR-OLD SPANISH-ENGLISH BILINGUAL CHILD

\author{
Jonathan Robinson Anthony \\ San Francisco, California
}

2016

One of the most challenging aspects of assessing the phonological development of bilingual children is finding a method that is both ecologically valid and normatively informative. This study investigates if spontaneous speech samples from a SpanishEnglish bilingual child give clinically relevant information that is not typically available through traditional assessment methods. In this single subject case study, the researcher collected spontaneous speech samples from a 5-year-old, SpanishEnglish bilingual child. The speech samples were transcribed and evaluated to determine relation to established customary ages of production and levels of phonological complexity in both target languages. The results of this study indicate that spontaneous speech samples may be just as effective as elicited speech samples in offering comparisons to customary ages of production and phonological complexity for bilingual children.

I certify that the Abstract is a correct representation of the content of this thesis.

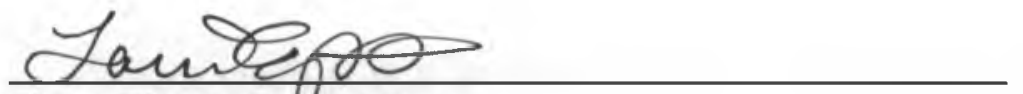

Chair, Thesis Cothmittee

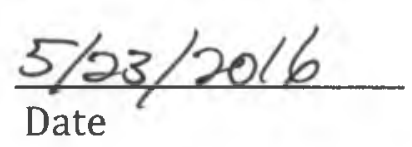




\section{PREFACE AND/OR ACKNOWLEDGEMENTS}

I would like to thank my committee members for their time, wisdom, and patience, my research assistants for their hard work, and my family, Eric and Mabel, for their support. 


\section{TABLE OF CONTENTS}

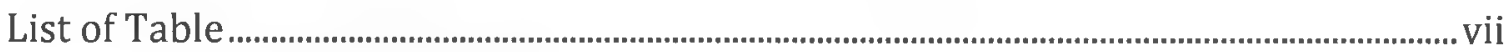

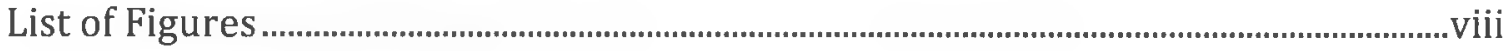

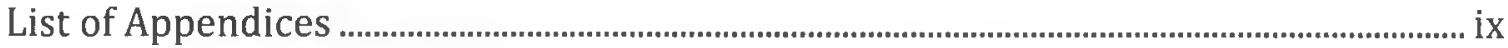

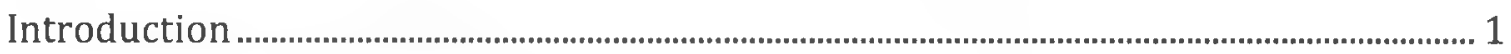

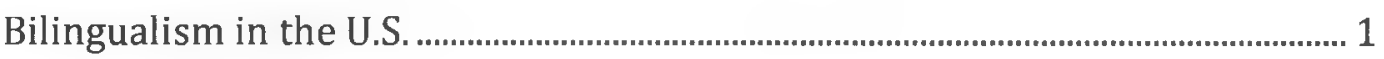

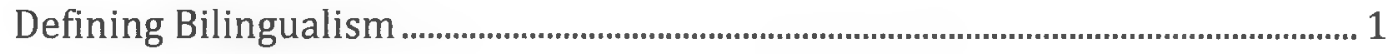

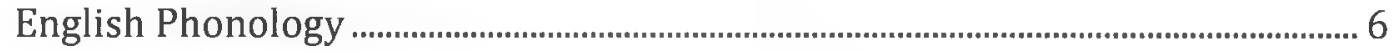

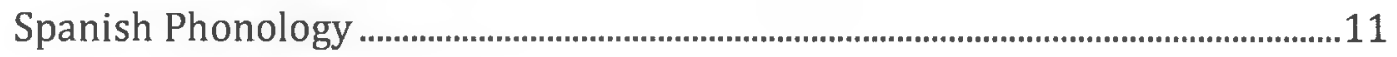

English and Spanish Comparison................................................................................... 15

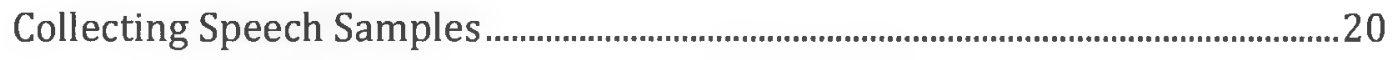

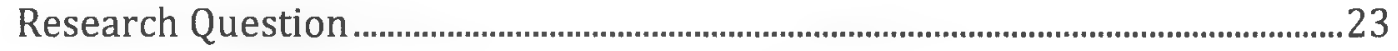

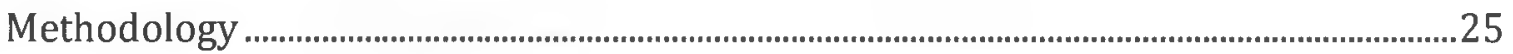

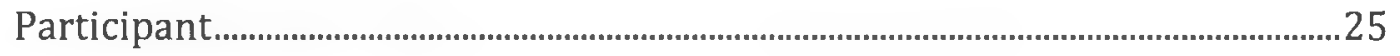

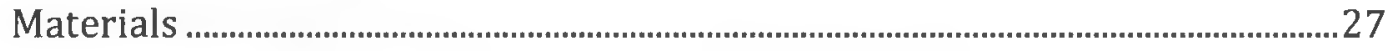

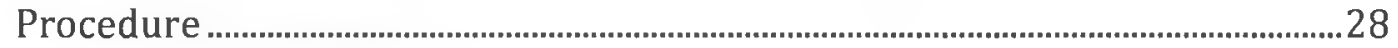

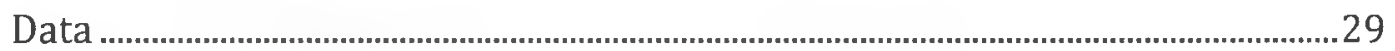

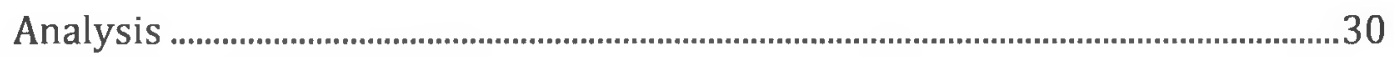

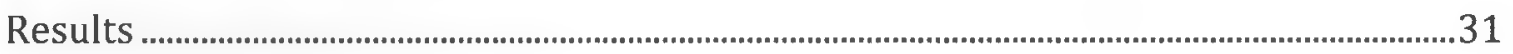

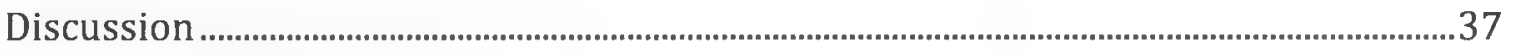

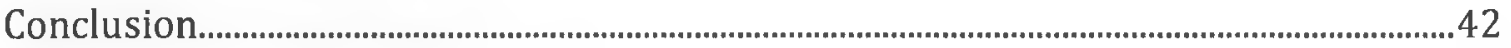

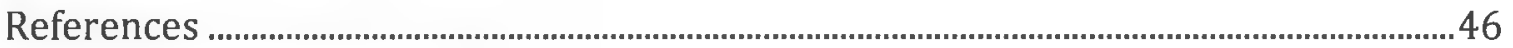

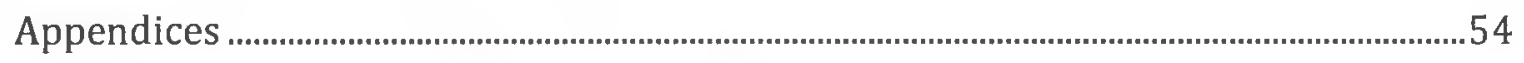




\section{LIST OF TABLES}

Table

Page

1. Comparison of Spanish and English Phonemic Inventories....................................15

2. English and Spanish Inventories and Complexity..................................................32

3. Speech Sound Accuracy........................................................................................

4. Number of Attempts of Speech Sounds.................................................................. 
LIST OF FIGURES

Figures

Page

1. Language Proficiency Rating Scale ................................................6

2. English Phonetic Inventory .................................................................... 7

3. Customary Ages of English Consonant .................................................... 10

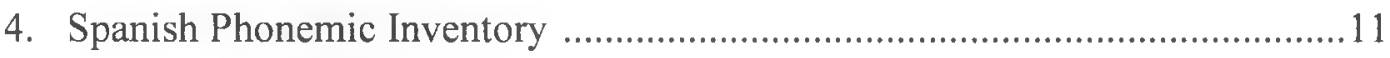

5. Acquisition of Spanish Consonants ........................................................... 14

6. English Levels of Phonetic Inventory Complexity..................................... 19

7. Spanish Levels of Phonetic Inventory of Complexity.................................20

8. Hierarchy of Phonological Levels of Complexity........................................36

9. Bilingual Children's Phonetic Inventories for Spanish and English ................37 


\section{LIST OF APPENDICES}

Appendix

Page

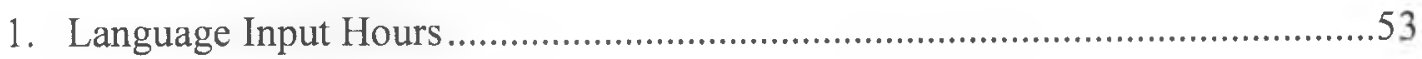




\section{Introduction}

Bilingualism in the U.S.

Speech and language disorders in early childhood are difficult to diagnose. Though cognitive development is considerably incomplete until young adulthood (Pujol, Reixach, Harrison, Timoneda-Gallart, Vilanoca, and Pérez-Alvarez, 2003; Casey, Giedd, and Thomas, 2000), the critical period for native or near native language development arguably ends before puberty (Hurford, 1991). Until the end of the critical period, marked by the onset of puberty, the ability to learn language is flexible, making it difficult to predict if some perceived language disorders are a phase or a condition. Clinicians, therefore, require normative data on the observed deviations in speech and language in order to draw conclusions based on clinical markers or signs. The normative data on English-speaking populations are well documented. However, research-based data on bilingual speakers is far behind considering the exponentially increasing population of bilinguals in the United States (Humes, Jones, and Ramirez, 2011; Shin and Kominski, 2010).

\section{Defining Bilingualism}

Bilingual language development can involve either sequential or simultaneous exposure to two distinct languages. Theories driving the examination of both types of bilingualism assume that a bilingual child acquires two language systems that interact 
with or influence one another (Genesee, 1989). In the case of simultaneous learning, both languages may be represented by one lexical inventory, which begins to differentiate around 3 years of age (Volterra and Taeschner, 1978). In a longitudinal study from early infancy to age 4;3 of two bilingual children, Volterra and Taeschner (1978) identified three stages through which the children became bilingual. In the first stage, the children had singular lexical systems that included words from either target language. In the second stage, the children differentiated lexicons, but utilized similar syntactic rules to both languages. It was during the third stage, around the age of 3 years old, that the children differentiated both lexicon and syntax in both languages. Later researchers would add to the definition of bilingualism, either sequential or simultaneous, by making distinctions between types of dual language learners based on age of exposure and social contexts. Schiff-Meyers (1992) states the following:

The first group includes infant bilinguality in which both languages are spoken to the child in early infancy. These children develop both languages simultaneously in naturalistic situations and can be truly bilingual in that their competence in both languages is often similar to monolinguals of each language. The second group includes preschool age children... These children hear only one language in the home and later are exposed to a second language elsewhere in the community of in a 
school-like situation. The third group includes school-aged children and adolescents who acquire second the second language in school (p. 29).

Collectively, groups two and three make up what researchers consider sequential bilinguals. Also, children who grow up bilingual, whether sequential or simultaneous, have a preference towards one language over another. The dominant language (L1) is typically the language that the child has received the most exposure. The secondary language (L2) may be the language spoken least frequently at home (for simultaneous bilinguals) or the language learned outside of the home, in the community, or in the school setting (for sequential bilinguals). The variability in exposure to multiple languages during a child's early years accounts for the uniqueness that children of similar language dyads may have. Place and Hoff (2011) sought to describe how the parents' native language (L1) influenced their children's bilingual exposure and how the variability in that exposure affects language development; in a study of the language diaries of 29 mothers of Spanish-English bilingual children, a self-report measure of the parents' English and Spanish development, and formal assessment of the children's language development, they found that children's language abilities were related to the amount and type of exposures to the target languages. While Spanish grammatical complexity showed a negative correlation with Spanish language input (due to floor effects in the children), the number of conversation partners with whom the children 
spoke and heard only English, as well as the percent exposure to native English speakers, were indicators of English language skills.

Parent report of language ability in determining bilingual status and level of participation in studies is invaluable. As Place and Hoff (2011) described the significance of language exposure to bilingual development, Pearson, Fernandez, Lewedeg, and Oller (1997) laid the groundwork for amounts of exposure required for adequate dual-language production. Pearson et al. (1997) sought to determine the relationship between language exposure and vocabulary learning. The researchers tape-recorded 25 Spanish-English infants for 5 years, from 4 months old to 60 months old, in their laboratory. The researchers additionally had parents and caregivers complete standardized parent report instruments to assess the vocabularies of the children and to quantify the type and amount of exposure the children were given in both target languages. The results of the study indicated that children who heard less than $20 \%$ of a target language were less willing to use that language in conversation. Furthermore, Pearson et al. (1997) proposed the following regarding their observations:

This pattern prompted the research staff to recommend that children whose exposure was less balanced than 75:25 not be considered for future bilingualism studies. This is not to say that some children with less exposure will not become bilingual or that all children with more exposure will, but that as a matter of 
practicality the elicitation of speech samples will be more efficient within those ranges (p. 56).

In addition to utilizing parent report to calculate percentages of language exposure, parent report using scaled scores can be beneficial in determining bilingual proficiency. Gutierrez-Clellen and Kreiter (2003) investigated the relationship between the amount of exposure to Spanish and English, grammatical performance, and parent and teacher report of bilingual ability. The researchers collected data from 57 secondgraders on grammar performance in both English and Spanish. They then compared the children's performances with parent and teacher reports of language proficiency on a 0 4 scale developed from Pena et al. (2003) (Figure 1). While language input as a predictor of grammatical performance varied between target languages (i.e. Spanish input predicted grammatical performance whereas English input did not strongly predict grammatical performance), the results of this study demonstrated that parent and teacher report correlated with grammatical performance, thereby implying that parent and teacher report serve as a reliable factor in determining bilingual status. 
Proficiency refers to how well the child speaks each language.

0 Cannot speak the indicated language, has a few words or phrases, cannot produce sentences, only understands a few words.

1 Cannot speak the indicated language, has a few words or phrase, understands the general idea of what is being said.

2 Limited proficiency with grammatical errors, limited vocabulary, understands the general idea of what is being said.

3 Good proficiency with some grammatical errors, some social and academic vocabulary, understands most of what is said.

4 Native-like proficiency with a few grammatical errors, good vocabulary, understands most of what is said.

Figure 1. from Pena et al. (2003); adapted from Restrepo (1998) and Gutierrez-Clellen and Kreiter (2003).

English Phonology

It can be inferred from the most recent census brief on language use in the United States that the majority of bilinguals in the US are Spanish-English speaking (Shin and Kominski, 2010). The same brief reported that English-alone was the language spoken at home for $82 \%$ of the population 5 years and older. The monolingual English-speaking 
child with typical development follows a well-researched and documented path of speech sound development. The standard American English language consists of 24 consonant phonemes categorized by place (bilabial, labiodental, dental, alveolar, postalveolar, palatal, velar, glottal), manner (plosive, nasal, fricative, affricative, glides, liquids) and voice (voiced, voiceless). Figure 2 demonstrates the complete English consonant phonemic inventory according to these three classifications with the exception of tap or flap manners as they are related to allophonic variations of standard phonemes.

ENGLISH PHONEMIC INVENTORY

Please remember that dialectal differences exist for each language and should be considered when using the phonemic charts.

\begin{tabular}{|c|c|c|c|c|c|c|c|c|}
\hline & 흠 & 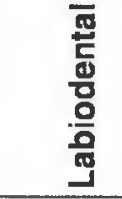 & 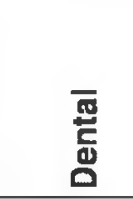 & $\frac{\frac{2}{x}}{8}$ & $\begin{array}{l}\frac{2}{0} \\
\frac{0}{0} \\
\frac{0}{3} \\
\frac{0}{0} \\
0 \\
0\end{array}$ & $\frac{\bar{\Phi}}{\underline{\mathbb{E}}}$ & $\frac{2}{\frac{\pi}{0}}$ & $\frac{\bar{t}}{\text { 흥 }}$ \\
\hline Plosive & $p \quad b$ & & & $t \quad d$ & & & $k \quad g$ & \\
\hline Nasal & $\mathrm{m}$ & & & $n$ & & & $\eta$ & \\
\hline Trill & & & & & & & & \\
\hline $\begin{array}{l}\text { Tap or } \\
\text { Flap }\end{array}$ & & & & & & & & \\
\hline Fricative & & $f \quad v$ & $\theta \quad \delta$ & s $\quad z$ & & $\int$ & & $\mathrm{h}$ \\
\hline Affricate & & & & & $t \int d s$ & & & \\
\hline $\begin{array}{l}\text { Glides } \\
\text { (Approximant) }\end{array}$ & $w$ & & & $r$ & & $j$ & & \\
\hline $\begin{array}{l}\text { Liquid } \\
\text { (Lateral } \\
\text { Aporoximant) }\end{array}$ & & & & 1 & & & & \\
\hline
\end{tabular}

Figure 2. adapted from Edwards' (2003) English Phonemic Inventory; from English

Phonemic Inverntory. (n.d.). Retrieved November 4, 2015, from

http://www.asha.org/uploadedFiles/practice/multicultural/EnglishPhonemicInventory.pdf 
Although allophones are not included in the English Phonemic Inventory, they are important to discuss because of their relevance to natural speech. Allophones are one or more variations of a specific phoneme. A phoneme is a speech sound that can be differentiated for meaningful parts of speech. For example, the phonemes $/ \mathrm{p} /$ and $/ \mathrm{b} /$ are distinctly different in English; while they share similar places and manners of articulation, they are perceived as separate speech sounds due to the voiceless quality of the $/ \mathrm{p} /$ phoneme and the voiced quality of the $/ \mathrm{b} /$ phoneme. As a consequence of this distinction, English language listeners perceive meaningful differences in words like "pat" and "bat," resulting in minimal pairs. However, allophonic variations of a phoneme do not change the perceived meaning of speech sounds in English.

One common allophonic variation, of the /t/ and /d/ phonemes in the English language, is the tap or flap $/ \mathrm{d} /$ phoneme. The $/ \mathrm{t} /$ and $/ \mathrm{d} /$ phonemes share similar places and manners of articulation (i.e., the tip of the tongue making contact with the alveolar ridge, the flow of air is temporarily halted to produce a plosive speech sound), but they differ in voicing (i.e., /t/ is a voiceless consonant sound and /d/ is a voiced consonant sound). However, both /t/ and /d/ share the allophonic variation / $/$ when they are produced medially in intervocalic positions in words, such as in the word "city" or "lady." Klein and Altman (2002) examined the production of medial /t/ and /d/ allophones in four English speaking children between the ages of 2 and 5 years old for a duration of 38 months. The children produced the targeted $/ \mathrm{t} /$ and $/ \mathrm{d} /$ phonemes by either being shown a picture of a single word or by participating in a play situation that was fixed to elicit the 
target sounds. While the children of this study used a total of 15 variations to produce the medial /t/ and /d/ sounds, Klein and Altman (2002) found that one of the most common allophonic variations used was the tap or flap /c/. It is difficult to establish the age of customary production of allophones given their noncontrastive nature; however, Klein and Altman's (2002) study may indicate that the tap or flap/f/allophone in English is an early to middle developing sound based on the ages of the children.

It is important to note that all sounds are not acquired at the same age. Sander (1972) utilized existing data on the articulation inventories of English speaking children from Wellman, Case, Mengert, and Bradbury (1931), Poole (1934, 1938), and Templin (1957) in order to investigate when speech sounds are learned. Sander's (1972) investigation of age of English consonant acquisition revealed some sounds are customarily produced (i.e., correctly produced $50-90 \%$ of time in two out of three positions, including initial, medial, and final) earlier that others. For example, nasal sounds such as $/ \mathrm{m} \mathrm{n} /$ and stops such as $/ \mathrm{p} \mathrm{b}$ /, are customarily produced with high accuracy at or before the age of 3 years old. Fricatives and affricative sounds may take as long as 7 or more years before customary production is accomplished with high accuracy. Figure 3 demonstrates the acquisition patterns of English consonants; each bar begins when a sound is produced accurately more than $50 \%$ of the time and ends when each sound is produced accurately at least $90 \%$ of time. 


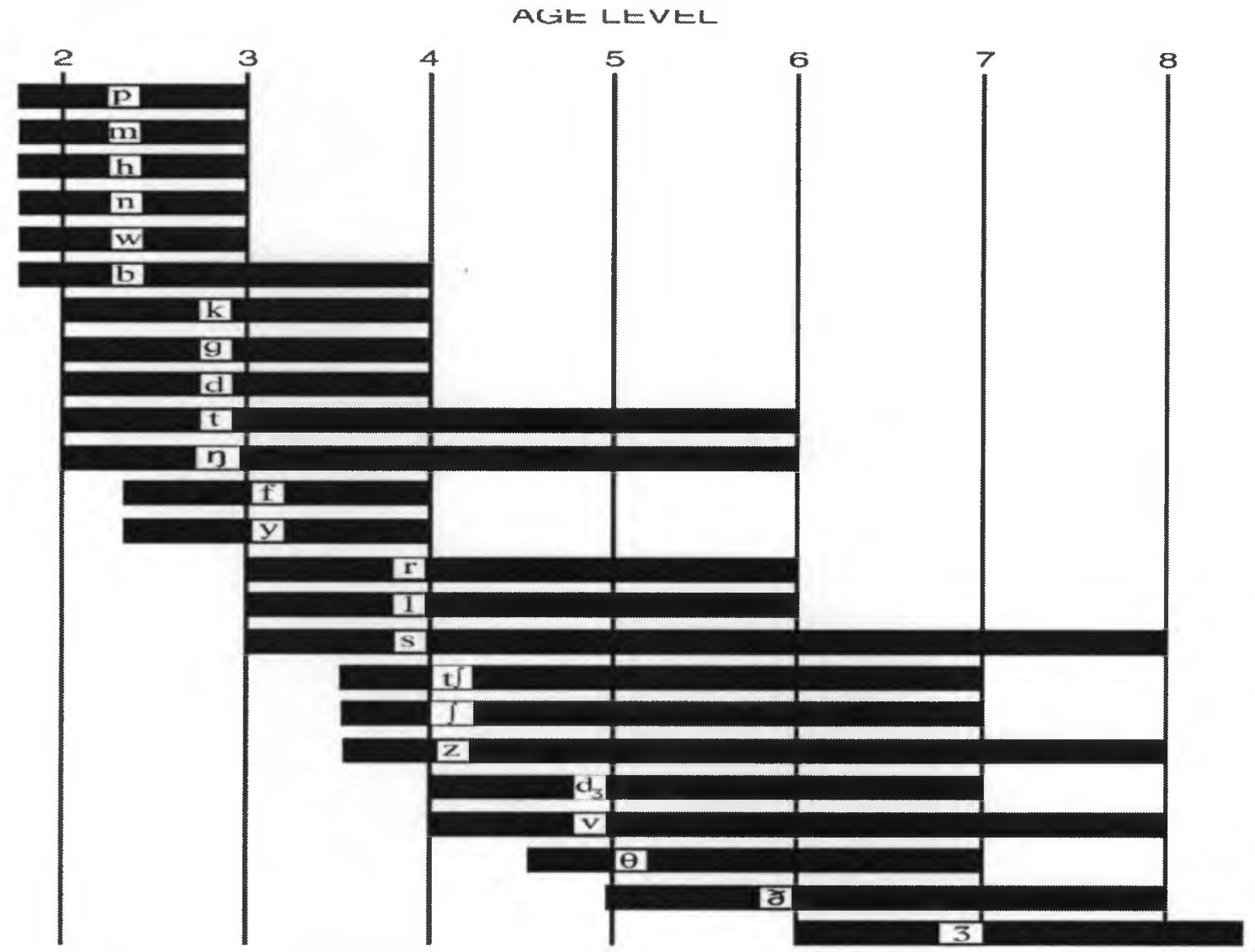

Figure 3. from Sander's (1972) customary ages of English consonants

Subsequent research on English speech sound development, while yielding slightly different results, corresponds to Sander's (1972) customary age of acquisition. Prather, Hedrick, and Kern (1975) completed a study on the speech sound development of 147 two to four year olds using picture naming tasks. While their research may suggest that English speech sounds develop earlier than previously assumed by Sander's (1972) research, their findings closely matched the customary ages of production outlined by Sander (1972). 


\section{Spanish Phonology}

Spanish speech sounds differ from English speech sounds in that there are 18 standard consonants. Similar to English, Spanish speech sounds are categorized by place, manner, and voice. In contrast to English speech sounds however, Spanish speech sounds do not include dental $(/ \theta /$ and $/ ð /)$ and glottal $(/ \mathrm{h} /)$ places of articulation and do include trill $(/ \mathrm{r} /)$ and tap or flap $(/ \mathrm{f} /)$ manners of articulation. Figure 4 demonstrates the Spanish consonants.

SPANISH PHONEMIC INVENTORY

Please remember that dialectal differences exist for each language and should be considered when using the phonemic charts.

\begin{tabular}{|c|c|c|c|c|c|c|c|c|}
\hline & $\begin{array}{l}\overline{\frac{\mathbf{m}}{\circ}} \\
\overline{\bar{m}} \\
\overline{\bar{m}}\end{array}$ & $\begin{array}{l}\overline{9} \\
\text { 동 } \\
\text { 몸 } \\
\text { 음 }\end{array}$ & $\begin{array}{l}\text { 焉 } \\
\text { 口̃ }\end{array}$ & $\begin{array}{l}\frac{2}{\overline{0}} \\
\frac{\Phi}{2} \\
\frac{1}{4}\end{array}$ & 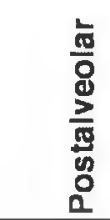 & 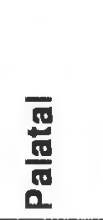 & $\frac{\frac{2}{\pi}}{\frac{5}{0}}$ & 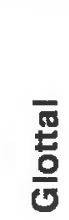 \\
\hline Plosive & $p \quad b$ & & & $t \quad d$ & & & k $\quad \mathrm{g}$ & \\
\hline Nasal & $\mathrm{m}$ & & & $n$ & & n & & \\
\hline$\overline{\text { Trill }}$ & & & & $r$ & & & & \\
\hline $\begin{array}{l}\text { Tap or } \\
\text { Flap }\end{array}$ & & & & $\Gamma$ & & & & \\
\hline Fricative & & $f$ & & $\mathrm{~s}$ & & & $x$ & \\
\hline Affricate & & & & & t5 & & & \\
\hline $\begin{array}{l}\text { Glides } \\
\text { (Approximant) }\end{array}$ & $w$ & & & & & j & & \\
\hline $\begin{array}{l}\text { Liquid } \\
\text { (Lateral } \\
\text { Approximant) }\end{array}$ & & & & 1 & & & & \\
\hline
\end{tabular}

Figure 4. Adapted from Goldstein's (2000) Cultural and Linguistic Diversity Resource 
Guide for Speech-Language Pathologists; from Spanish Phonemic Inventoy. (n.d.). Retrieved November 4, 2015, from http://www.asha.org/uploadedFiles/practice/multicultural/SpanishPhonemicInventory.pdf

There are a few exceptions to the Standard Phonemic Inventory that are made to account for dialect differences and allophonic variations; these speech sounds are the glottal voiceless fricative $/ \mathrm{h} /$, the palatal voiceless fricative $/ \mathrm{J} /$, the dental voiceless fricative $/ \theta /$, the dental voiced fricative $/ \delta /$, the bilabial voiced fricative $/ \beta /$, and the velar voiced fricative $/ \mathrm{\gamma} /$. The $/ \mathrm{h} /, / \mathrm{J} /$, are $/ \theta /$ phonemes are specific to the various dialects of Spanish. In Caribbean Spanish-speaking countries (Cuba, Dominican Republic, Puerto Rico), the $/ \mathrm{f} /$ and $/ \mathrm{s} /$ phonemes are commonly realized as the glottal fricative $/ \mathrm{h} /$ (Guitart, 1997). For example, words like asta and afta are articulated as /ahta/. In the country of Argentina, the $/ \mathrm{j} /$ phoneme is commonly realized as the $/ \mathrm{J} /$ phoneme, which is referred to as "sheísmo" (Chang, 2008). Words like cebolla (/seßoja/) and llave (/jaße/) are articulated as $/ \mathrm{se} \beta o \mathrm{a} a /$ and $/ \mathrm{Ja} \mathrm{e} /$. In Spain, the $/ \theta /$ phoneme is realized for the $/ \mathrm{s} /$ phoneme with the graphemes "ce," "ci," and "z" (Azevedo, 2009). In words like caza (/kasa/) and hacer (/aser/), the $/ \mathrm{s} /$ phoneme is replaced with $/ \theta /$, resulting in the words $/ \mathrm{ka} \theta \mathrm{a} /$ and $/ \mathrm{a} \theta \mathrm{er} /$. The $/ \mathrm{J} /, / \mathrm{B} /$, and $/ \mathrm{\gamma} /$ phonemes are common across most Spanish dialects as allophonic variations to their plosive counterparts /d/, /b/, and /g/ (Lord, 2005). As opposed to a complete stop in airflow required to produce the burst of air characteristic of plosive English sounds, the Spanish approximation of $/ \mathrm{d} /, / \mathrm{b} /$, and $/ \mathrm{g} /$ alternatively restrict constant airflow, creating sounds characteristic of English fricatives; hence, /d/, /b/, and 
$/ \mathrm{g} /$ are realized as $/ \delta /, / B /$, and $/ \mathrm{y} /$. These transformations are considered allophonic pairs as there are no contrasts in meaning between words where speakers may use one sound or the other (e.g., veinte articulated as /beinte/ or/Beinte/).

Spanish speech sounds are developed quite differently from English speech sounds in their respective monolingual populations. Jimenez (1987) looked to determine the customary age of Spanish speech sound acquisition utilizing similar methods to Prather et al. (1975). Jimenez (1987) tested the articulation skills of 120 Spanishspeaking children of Mexican decent, ranging from ages 3 to 5 years old, using drawings and delayed imitation. Previous to Jimenez (1987), research in Spanish phonology focused on the age of mastery versus the age range at which children accurately produced particular speech sounds with 50-90\% accuracy. Figure 5 demonstrates such findings from Jimenez (1987). 


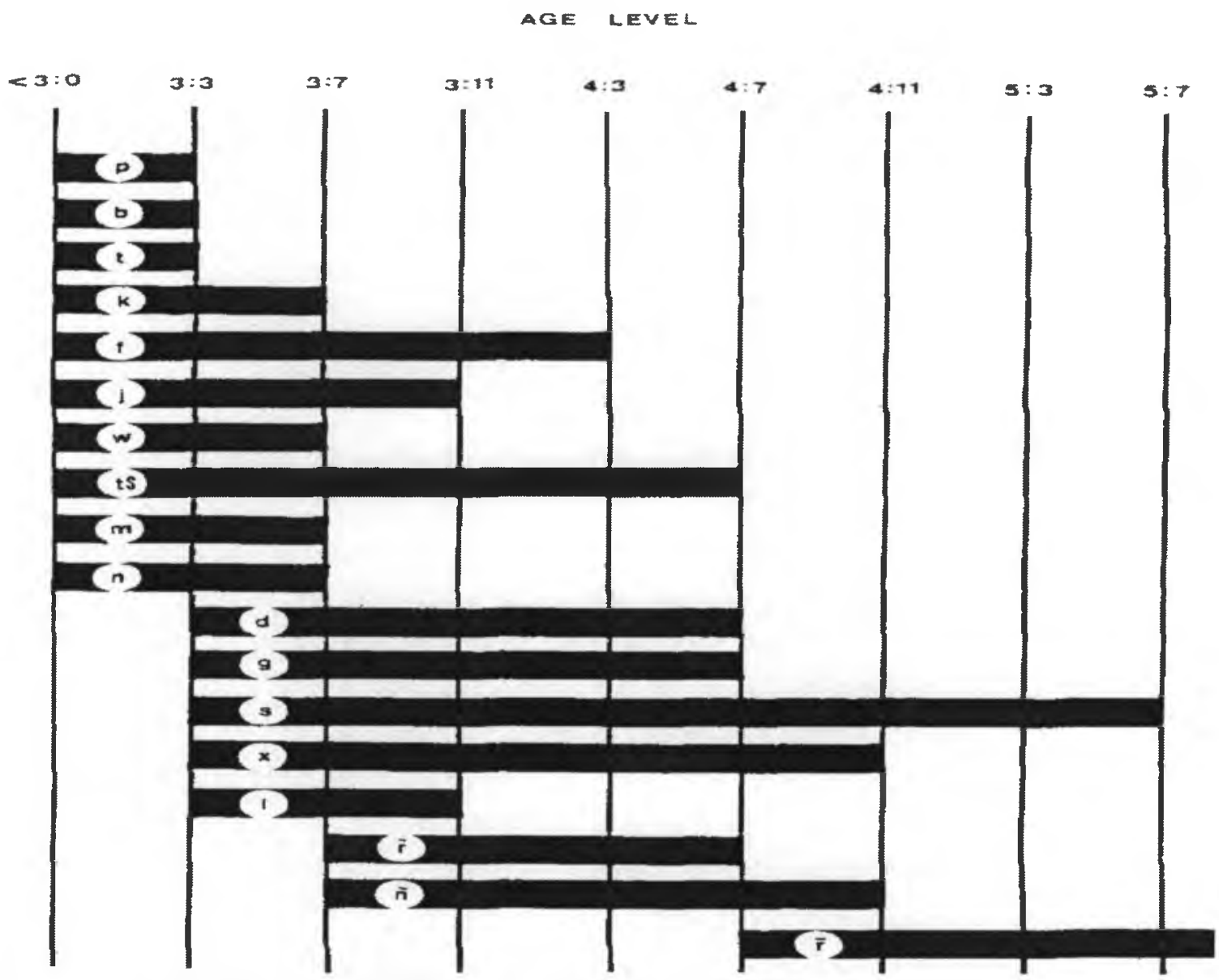

Figure 5. from Jimenez's (1987) Acquisition of Spanish Consonants

Spanish speaking children, as it is illustrated, have customary production with high accuracy of most of the phonemes of the language before the age of 6 years old with the exception of the trill /r/. While Jimenez's (1987) study is limited to a base age of 3 years old, Goldstein and Cintron's (2001) would suggest that Spanish-speaking 2-year-olds have at least minimal accuracy in customary production of stops (/p b t d k/) and nasal sounds $(/ \mathrm{m} \mathrm{n} /)$. 


\section{English and Spanish Comparison}

The Spanish and English languages have similarities in 14 consonant sounds.

Table 1 illustrates the comparison of the standard phonemic inventories of Spanish and English.

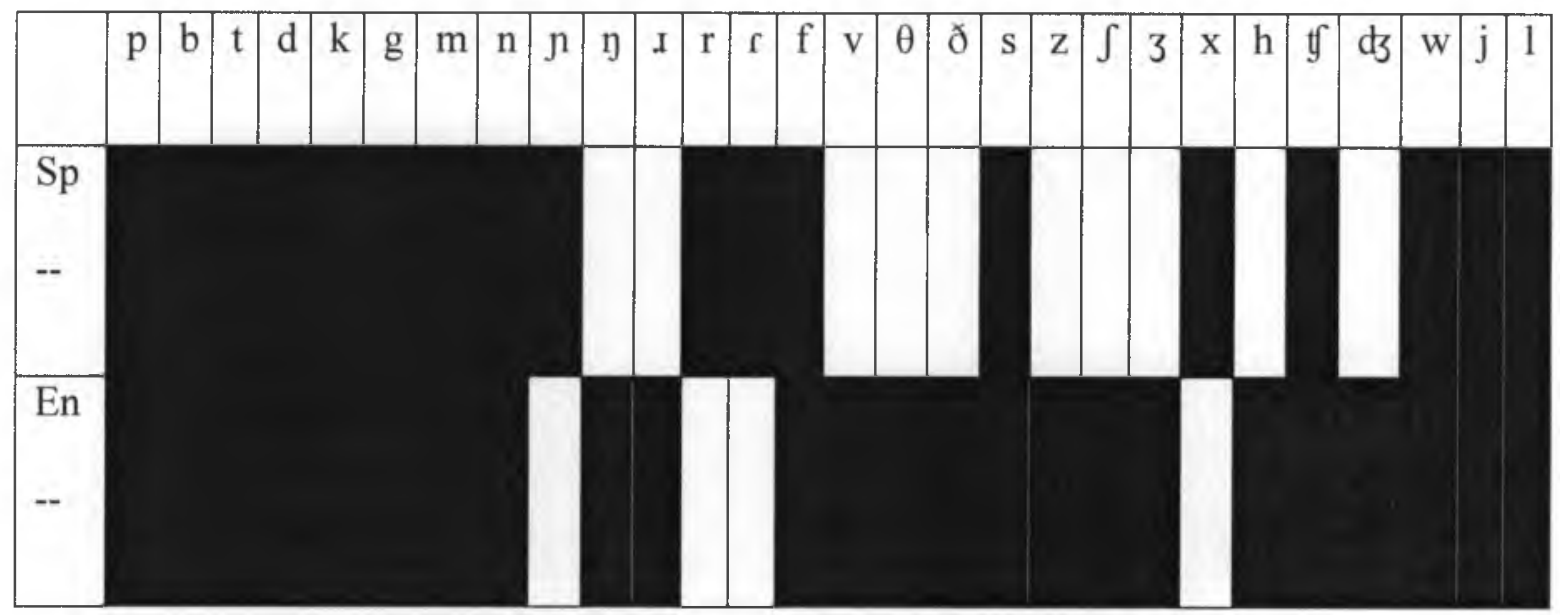

Table 1. Comparison of Spanish and English Phonemic Inventories

With only a handful of phonemes that do not overlap, Spanish and English are very close in phonemic composition; however, it is clear that development of each individual sound varies between languages. For example, the research illustrates that Spanish speaking children will have a higher level of customary production of $/ 1 /(3: 3-3: 11$ years $)$ and $/ \mathfrak{g} /$ ( $3-4: 7$ years) at an earlier age than English speaking children $(3-6$ years and $\sim 3: 6-7$ years, respectively). Also, almost all Spanish-speaking children will have high customary production of their complete consonant inventory before the age of 6 years old while English-speaking children will only have high customary production of $\sim 38 \%$ of the English consonant inventory by this same age. How is it, then, that researchers can 
account for bilingual language development?

Emerging literature suggests that bilingual children may develop phonological inventories that are dissimilar to the phonological inventories of their monolingual peers. Goldstein and Washington (2001) investigated the phonological patterns of SpanishEnglish bilingual 4 year olds. Eliciting target words with the use of photographs, the researchers collected data on both English and Spanish inventories for each of 12 children. The results of this study indicated that that the speech sound error patterns presented by bilingual children were different than those of both monolingual Spanishand monolingual English-speaking children. Studies of bilingual children acquiring a variety of languages have presented similar evidence for differential phonology development in bilinguals (Farsi-English, Keshavarz and Ingram, 2002; Chinese-English, Holm and Dodd, 1999; Russian-English, Gildersleeve-Neumann and Wright, 2010).

Additionally, traditional investigations of language development have focused on the age of mastery or age of customary production of individual speech sounds. However, there is convincing evidence that suggests that a focus on speech sound classes can more accurately illustrate bilingual language complexity. Traditional investigations of phonemic inventories have focus on mastery of individual speech sounds as part of a "checklist." For example, a child may be lacking complete mastery of the /x/ phoneme, but this alone does not describe the quality of the child's inventory as a whole. Rather, defining complexity of phonemic inventories based on classes of speech sounds illustrates an ability to create phonemes. 
Dinnsen, Chin, Elbert, and Powell (1990) created a hierarchy of English language sound classes based on the division of phonetic features. Speech sounds were organized based on place, manner, and voicing. Using the speech samples from 40 Englishspeaking children with phonological disorders, the researchers created five phonetic inventories of increasing complexity. Speech sounds were included in each child's inventory if the sound was produced at least twice, regardless of accuracy in targeted words. Level A included the presence of stops, nasals, and glides. Stops and nasals were distinguished from glides by \pm consonantal. Stops were distinguished from nasals based on \pm sonorant. Labial and alveolar positions, the only two places of articulation for level A stops, were distinguished from one another based on \pm coronal. Level B elaborated on level A by adding voicing and placement of stops distinctions. Voicing was distinguished by \pm voicing, and positions of stops were distinguished by \pm anterior. Level $\mathrm{C}$ added manner of articulation distinctions to include fricatives and affricates. Fricatives were distinguished from stops based on \pm continuant, and affricates were distinguished from stops by \pm delayed release. Level $\mathrm{D}$ added liquid consonants by distinguishing sonorant consonants by properties of \pm nasality. Level $E$, the most complex level, added distinction of \pm stridency and \pm laterality.

Following Dinnsen et al.'s (1990) study of English levels of complexity, Catano, Barlow, and Moyna (2009) created the foundation for Spanish phonetics levels of complexity. The researchers of this study similarly organized monolingual Spanishspeaking children's speech sound productions into sound classes. Catano et al. (2009) 
found that Spanish sound class levels of complexity were similar to English speech sound class levels of complexity with a few exceptions: Level A included the liquid phoneme /1/ ( \pm nasal); Level $\mathrm{D}$ was based on the presence of either $/ \mathrm{r} / \mathrm{or} / \mathrm{f} /$ and Level $\mathrm{E}$ required the presence of all three /l/, /r/ and / $/$ phonemes. Shortly after, Fabiano-Smith and Barlow (2010) examined how dual-language interactions contribute to phonological acquisition in Spanish-English bilingual 3 to 4 year olds, with a focus on what typical speech sound inventories of such bilingual children included. Using the Levels Inventories outlined by Dinnsen et al. (1990) in English (Figure 6) and Catano et al. (2009) in Spanish (Figure 7), the researchers employed picture-naming tasks in both target languages to collect and analyze phonological inventories from each of the children. The results of their study indicated that the bilingual children had phonological inventories in either language that were just as complex as the inventories of their monolingual peers. While this study does not take into consideration measures of accuracy of individual phonemes (i.e., the study only accounts for the presence of a particular phoneme in each target language and does not refer to the accurate production of speech sounds in a target word), the results are nevertheless significant in comparing bilingual to monolingual ability in speech class production. 


\section{Level Featural difrerences Sample inventories}

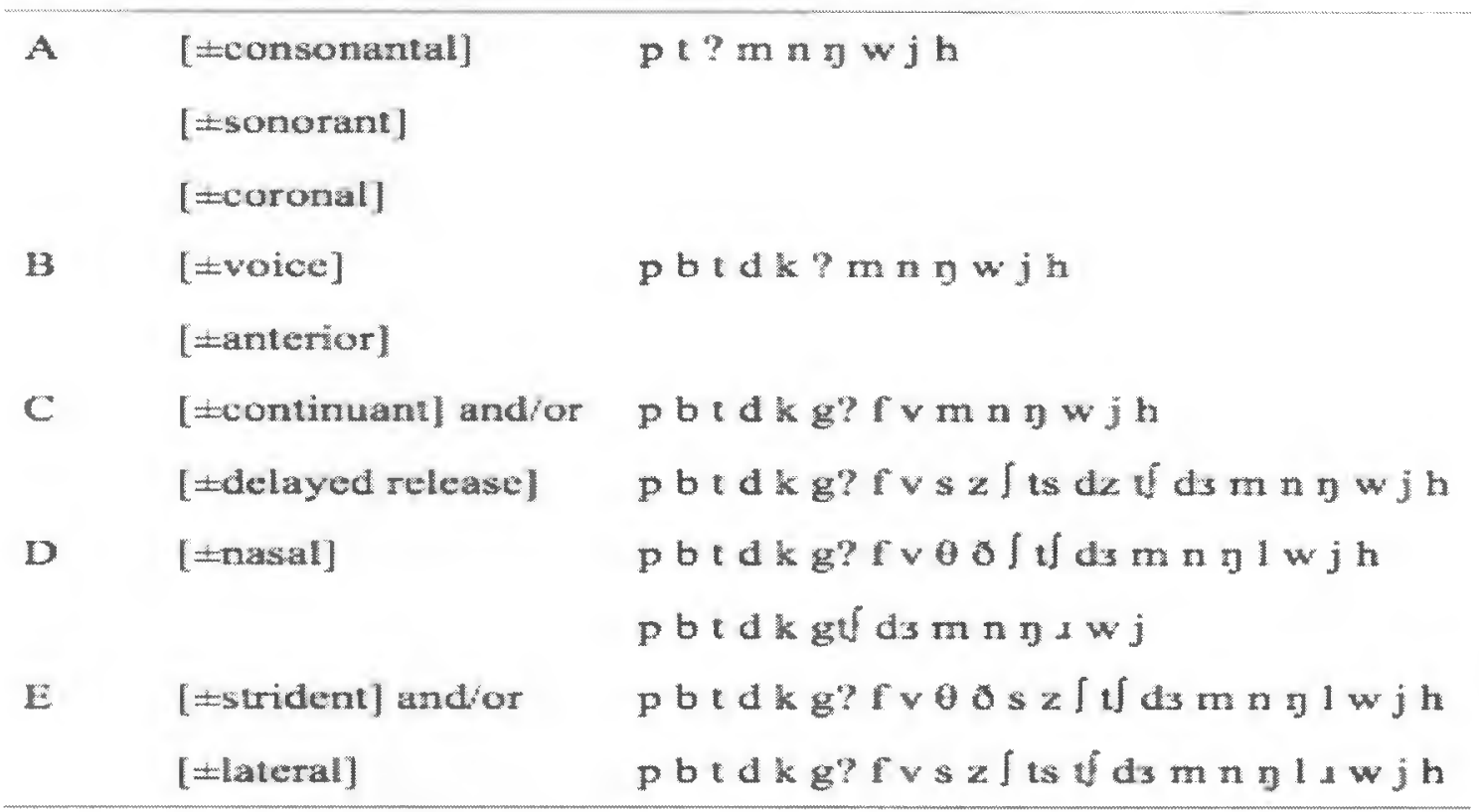

Figure 6. adapted from Dinnsen et al. (1990) English levels of phonetic inventory of

complexity; from Catano et al. (2009). 


\begin{tabular}{|c|c|c|}
\hline Level & Featural differences & Sample inventories ${ }^{\text {a }}$ \\
\hline \multirow[t]{3}{*}{ A } & [Isonorant] & $27: b \operatorname{tgn} \beta 1$ \\
\hline & [土coronal] & \\
\hline & {$[=$ nasal $]$} & \\
\hline \multirow[t]{2}{*}{ B } & [Ifvoice] & 18: $p \mathrm{tdkgmnlj}$ \\
\hline & [zanterior] & \\
\hline \multirow[t]{3}{*}{ C } & [-continuan:] and/or & 35:pbtakgfshmnj w $\beta$ oj \\
\hline & {$[$ delayed release] } & 19:pbtkgلmn!j \\
\hline & & $11: p b i d k \Phi s \times\{m n n 1 \beta j$ \\
\hline \multirow[t]{3}{*}{$\mathrm{D}$} & [-lateral] andior & 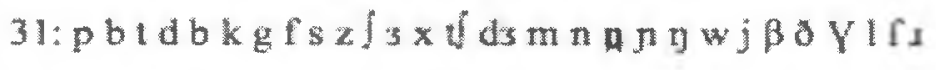 \\
\hline & {$[ \pm$ strident] } & 8: pbtakgresxddsmnlw $\beta$ oj \\
\hline & & 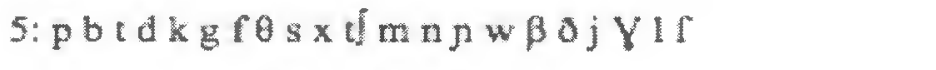 \\
\hline E & {$[=$ tense $]$} & 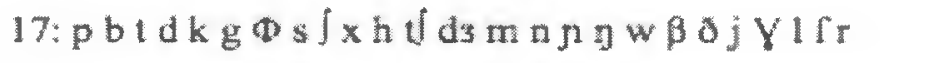 \\
\hline
\end{tabular}

Figure 7. from Catano et al. (2009) Spanish levels of phonetic inventory of complexity

\section{Collecting Speech Samples}

At present, the most salient limitation of research concerning bilingual language development is the method of collecting data. Researchers typically aim to compare data collected from individual subjects to groups. In order to do so with validity, however, standardized tasks must be employed in order to justify comparisons. One of the most popular types of standardized assessments used by researchers of phonological development is picture-naming tasks (e.g., Dinnsen et al., 1990; Fabiano-Smith and Barlow, 2010; Fabiano-Smith and Goldstein, 2010; Gildersleeve-Neumann and Wright, 2010; Goldstein et al., 2005; Jimenez, 1987; Wellman et al., 1931). These tasks are 
structured to elicit language samples from children by showing them pictures or photographs and asking the question, "What is this?" Picture-naming tasks are one example of a few speech elicitation techniques (e.g., imitation, reading), and they are not without their benefits. For example, these tasks are well structured and researchers are generally guaranteed to collect full samples of targeted inventories. Also, researchers can analyze the same tasks across multiple studies and participants. Elicited speech tasks are particularly advantageous for reasons as such, though they are not perfect. One issue with eliciting speech sound samples is the conflict of analyzing words outside of their natural contexts. By the age of three, children typically combine two or more words in natural speech. Eliciting single words from children beyond this age, while it may yield speech sounds suitable for analysis, loses the inherent title of "natural language."

Another issue with elicited speech tasks is the validity of what is being tested. While some children may have large enough expressive vocabularies to adequately participate in picture-naming tasks, words that are not highly used in natural language may be inaccurately expressed. Edwards and Beckman (2008) evaluated word-initial consonant accuracy from elicited, single word productions from 2 to 3 year olds across languages (English, Cantonese, Greek, and Japanese). They specifically evaluated the phonotactic probability, the frequency of target consonant-vowel (CV) sequencing, of these single words. The researchers then compared the phonotactic frequeny of $\mathrm{CV}$ clusters to measurements of accuracy. Edwards and Beckman (2008) found that lowfrequency $\mathrm{CV}$ sequences were produced less accurately than high-frequency $\mathrm{CV}$ 
sequences, accounting for $46 \%$ of the consonant accuracy variance in English. They additionally illustrate that the Goldman Fristoe Test of Articulation - 2 (GFTA-2; Goldman and Fristoe, 2000), a common assessment tool using in speech assessments, includes the target word cup $(/ \mathrm{k} \Lambda-/)$; this $\mathrm{CV}$ sequence appears in less frequently in English words as opposed to the $/ \mathrm{kæ-} / \mathrm{CV}$ sequence.

The alternative to eliciting speech samples for research in phonologic development is using a more natural approach: a spontaneous speech sample. Spontaneous speech sampling is characterized by unprompted, connected, and typically conversational speech. Opposite to elicited speech tasks, spontaneous speech samples do not use standardized target words to collect speech sound data. These speech samples are typically collected by recording the verbalizations of child participants in some familiar environment of activity. Set-up does not require the creation of a wellstructured list of target sounds; rather, participants are allowed and encourage to speak as freely as possible. One of the advantages of collecting data via spontaneous speech sampling is that the samples are more likely to be ecologically valid. Another advantage is that the collection of data in connected speech can highlight other aspects of language, such as morphology, syntax, and prosody.

Spontaneous speech sampling does have its limitations as well. One such limitation is that researchers are not guaranteed to gather samples that illustrated the full phonological inventory of participants. For example, a child may be recorded over various sessions, yet there may not be an instance of the child uttering words containing 
the /3/ phoneme (even though the child may have this phoneme in her inventory). Another such limitation is that data are not standardized - i.e., the same target words are not evaluated over multiple studies or participants. Furthermore, the amount of time and work that goes into transcribing and analyzing spontaneous speech samples may far exceed that required for transcribing and analyzing elicited speech, especially when collecting data for multiple participants. Although there are some downfalls to spontaneous speech sampling, there is not enough research to suggest that elicited speech samples demonstrates better the natural abilities of a child, as opposed to spontaneous speech samples.

\section{Research Question}

As the knowledge of speech and language development and disorders in bilingual populations expands, so do the clinical implications. It is well documented that bilingual children are often over- or under-identified as having language impairments due to the employment of clinical markers in the identification process that are specific to monolingual language productions and that are ill-suited for assessing bilingual speakers (Lidz and Pena, 1996; Bedore and Pena, 2008; Kritikos, 2003). Additionally, speechlanguage pathologists feel challenged and uncomfortable in serving and assessing children of linguistically diverse backgrounds using current research-based practices (Kimble, 2013; Pieretti and Roseberry-McKibbin, 2015). Future research can alleviate 
these issues by creating more authentic and representative ways to address speech and language development and disorders in linguistically diverse populations.

Traditional research has focused on the age of mastery or the age of customary production of speech sounds when evaluating child language development. Researchers have evaluated the abilities of typically developing monolingual children in efforts to create normative timelines for phonetic inventory development. However, given the prevalence of children being raised in multilingual environments, further research is needed on the typical abilities of children from diverse language backgrounds. Furthermore, the manner in which researchers have traditionally evaluated language development may not accurately illustrate children's abilities. An investigation of speech sound classes and speech sound complexity may provide more relevant clinical implications than assessments of single phonemes within an inventory.

Additionally, while research has benefited from the use of standardized assessments in collecting data, elicited speech samples, such as those produced via picture-naming tasks, may not accurately represent children's natural ability. Elicited speech samples require the isolation of words, which contradicts the natural production of connected speech. Also, as elicited speech samples are prompted, the target words that are produced may not validly stimulate children's true phonetic inventories due to variances in phonotactic frequencies, for example. While spontaneous speech samples only access what children produce without prompts and may not be fully representative 
of a child's speech sound repertoire, it is argued that they provide clinically relevant information that represents bilingual children's functional speech sound production.

This current study therefore poses the following question: does a spontaneous speech sample and analysis offer clinically relevant information about a bilingual child's phonological inventory that is not typically available through traditional assessment methods?

\section{Methodology}

\section{Participant}

The participant was a 5-year-old, typically developing, English-Spanish-speaking child living in southern California. The child's mother identified American English and Argentinean Spanish as the principal languages spoken at home. Mexican Spanish was identified as the secondary dialect of Spanish spoken with friends and the community. In the home, the participant was regularly expected to speak Spanish. The mother, although bilingual, only spoke Spanish while at home. If, for example, the child made requests in either English or Spanish, the mother would respond in Spanish only. On few occasions, as described by the mother, English would be spoken at home when guest were visiting. Also, the participant regularly received Spanish input from her caregiver who was Spanish-English bilingual. Similar to the mother, the caregiver generally spoke to the participant in Spanish, regardless of the child making requests or statements in English or 
Spanish. In addition, the participant had regular interactions with her older sister. The older sister was identified to be Spanish-English bilingual, but primarily spoke English while at home and interacting with the participant of this study. Outside of the home, the child was regularly exposed to English. She attended pre-school where English is the primary language of instruction. There, the participant of this study is regularly exposed to informal and academic English language through her peers and teacher. The participant additionally spends regular time on the weekends in temple and other social environments. In temple, the child is exposed to ceremonial Hebrew, but English is used as the primary language throughout services and in the interactions of church members. Other social activities typically take place in the community (e.g., parks, shopping, birthday parties). While Spanish may be used intermittently between the mother and other adults, English is the typical language spoken when interacting in public. Overall, the child was described as having significant amounts of exposure to both target languages, with more exposure to English than Spanish.

The child was recruited using flyers distributed to the public in the greater Los Angeles region. Children are considered a vulnerable population and proper consent was obtained from the participant's parent. The parent agreed to an informal interview regarding the child's background information and history. The child recently began kindergarten and has had no prior history of speech-language related services. The parent reported that the child's developmental history was unremarkable, hitting what seemed to be appropriate milestones in language and cognition. The child was the second born; she 
had a sister who was 3 years older. The child was identified as Spanish-English bilingual utilizing scaled scores of proficiency, consistent with Pena et al. (2003), and measures of input, recommended by Pearson et al. (1997). The child's parent reported that the participant performs at level 4 in English (i.e., native-like proficiency with few grammatical errors, good vocabulary, understands most of what is said) and performs at level 3 in Spanish (i.e., good proficiency with some grammatical errors, some social and academic vocabulary, understands most of what is said). In order to measure the amounts percentage of input of each target language, the parent was asked to describe a typical week for the participant. Then, the parent was asked to describe the duration of those activities and the languages spoken during those activities. The child received an estimated total input of 68 hours per week in English and 40 hours per week in Spanish. The hours of exposure in each language were then divided by the total hours of activities to provide a 63:37 English-Spanish ratio of exposure on a weekly basis (see Appendix 1). This meets the criterion for bilingualism described above by Pearson et al. (1997), which describes the threshold for bilingualism as being at least $25 \%$ exposure to the less dominant language.

\section{Materials}

Voice recordings were obtained using an Olympus VP-10 audio recording device (Internal NAND flash memory: $4 \mathrm{~GB}$ ). The audio files were transferred onto a computer 
(MacBook Air) and converted to an uncompressed standard audio wave (.wav) at 44100

Hz. The files were password protected after being uploaded and edited in the audio editing software Audacity.

Procedure

Recordings took place in three settings across one week with various conversation partners. The first setting was in a designated play area in the participants' home. The participant was engaged in board and card games with her Spanish-English bilingual, elementary school aged sister and her Spanish-English bilingual caregiver. The second setting was the following day at the dinner table in the participant's home with her previously mentioned sister. The final setting was in the living room of the participant's home with the participant's mother 6 days following the initial session. The parent was educated on the purpose of the current study and instructed to interact with her child as natural as possible. The parent and caregiver were specifically instructed before the sessions to not elicit artificial sentences from the child (i.e., sentences or phrases that are otherwise inconsistent with daily conversations, such as Cómo se dice ? or Can you say___?). There were no instructions as to which language should be spoken. This was done intentionally as to not jeopardize the quality or quantity of Spanish or English naturally spoken by the child or her conversations partners. The audio recording device remained concealed in either the hand of the mother or the caregiver. 
Data

The researcher recorded a total of 41 minutes and 23 seconds of conversation. The data was later edited to remove the voices of the participant's conversation partners and gaps between conversations or vocalizations. Additionally, unintelligible speech was edited out of the data, either due to the quality of the recording or the interference of background noises. Final data included 8 minutes and 20 seconds of participant speech.

The data was transcribed along four layers (Müller, 2006). The first (1) transcription layer was performed based on utterances. There were a total of 121 utterances varying age-appropriately in length. The majority of the utterances initially transcribed were in English or some combination of English and Spanish. Spanish-only utterances account for 15 of the 121 samples transcribed. The second (2) transcription layer was performed to transcribe target utterances into the International Phonetic Alphabet (IPA). Individual words as parts of an utterance were transcribed to IPA based on Standard American English and Standard, Non-Castilian Spanish. Exceptions were made for dialect variances in English and in Spanish when transcribing for target utterance. For example, the / $\mathrm{t} /$ or $/ \mathrm{d} /$ phonemes in intervocalic positions are commonly expressed as tap or flap / / / in English (Klein and Altman, 2002). In Argentinean Spanish, the /j/ phoneme is commonly expressed as / $\mathrm{f}$ (i.e., sheísmo) in all word positions (e.g., $/ \mathrm{jo} / \rightarrow / \mathrm{So} /$, /amarijo/ $\rightarrow$ /amarifo/) (Chang, 2008). The third (3) and fourth (4) 
transcription layers were performed by independent research assistants. The audio files and IPA transcriptions were reviewed by one research assistant and evaluated for accuracy. The third layer transcription was then edited to include a two-field option (e.g., $\{r, 1\}]$ for perceived speech errors. A second research assistant was then given the audio files and edited third layer transcription; she listened to the audio files and chose one of the two possible perceived speech sounds for a target word. The fourth layer transcription and the second layer transcription were then compared for discrepancies. Both transcription layers were found to be in $95 \%$ agreement when compared at the single word level. Edits were made based on the discrepancies and a final transcription was created.

Analysis

Each consonant sound was counted and measured based on frequency in spontaneous speech and accuracy in target utterance. Allophonic and dialectal variations were taken into consideration and were not counted towards errors in accuracy. The speech sounds were then graphed and labeled specific to error types. As the speech sample only captures a single moment in time, customary age of production could not be established as the product of a longitudinal study; however, speech sound accuracy was compared to previous Sander's (1972) and Jimenez's (1987) outlines of customary ages of production in English and Spanish. This could reveal more information about the use 
of speech language sampling in relation to the use of elicited speech in customary age of production. Additionally, the phonetic inventory was derived from final transcription in order to illustrate the available speech sounds and their complexities in each target language. All sounds that were produced were included in the inventory. It is important to note that Dinnsen et al. (1990) and Catano et al. (2009) only included speech sounds in the inventories of their participants if a sound was produced more than once, regardless of word position or accuracy. Because of the unpredictable nature of spontaneous speech samples, the inventory of this study's participant only reflects speech sounds used in conversation at least once in each target language. Speech sound inventories in both target languages were then evaluated based on levels of complexity and rated based on English levels A-E and Spanish levels A-E according to Dinnsen et al. (1990) and Catano et al. (2009). The results of this analysis are discussed in the following sections.

\section{Results}

The Spanish and English inventories (and complexities) can be found in Table 2. The English inventory may reflect a more complete list of phonemic production as the participant's speech sample was characterized by $88 \%$ of utterances in English. The Spanish inventory is limited based on the length of sentences and amount of output. 


\begin{tabular}{|c|c|}
\hline English Inventory & 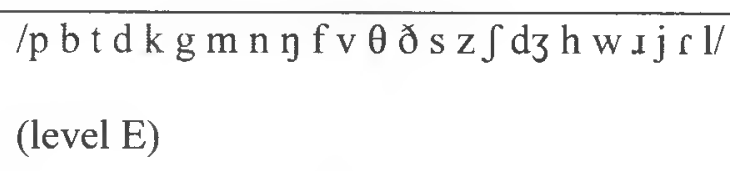 \\
\hline Spanish Inventory & $/ \mathrm{pb} \beta \mathrm{tkmngsxw \int rl/( \text {levelD) }}$ \\
\hline
\end{tabular}

Table 2. English and Spanish inventories and complexities

Table 3 demonstrates the percentage of accuracy with the production of each speech sound in both target languages. As depicted in the Table, the subject's customary production of sounds is commensurate with her monolingual Spanish and English peers with few exceptions. The low accuracy of voiced, interdental /ð/ does not align with expected outcomes based on the allophonic characteristics of /d/ in Spanish and expected customary production of at least $50 \%$ accuracy in English. Conversely, the current child has a high accuracy of the liquid /// in comparison to her monolingual English-speaking 
peers.

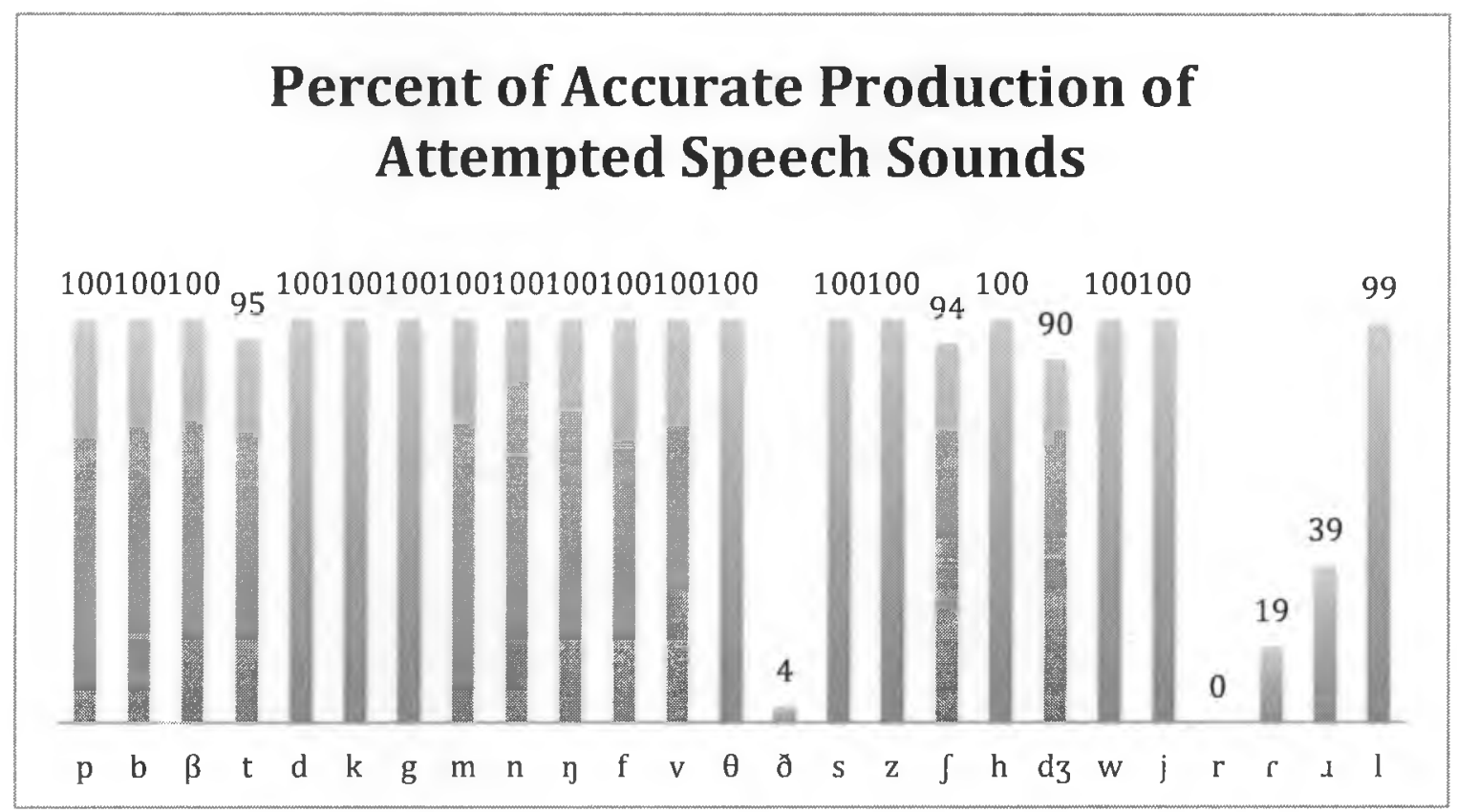

Table 3. Speech Sound Accuracy

Finally, the child in this current study did not produce the $/ \mathrm{r}$ / phoneme in her in her spontaneous speech sample (Table 4). 


\section{Number of Attempts of Speech Sounds}

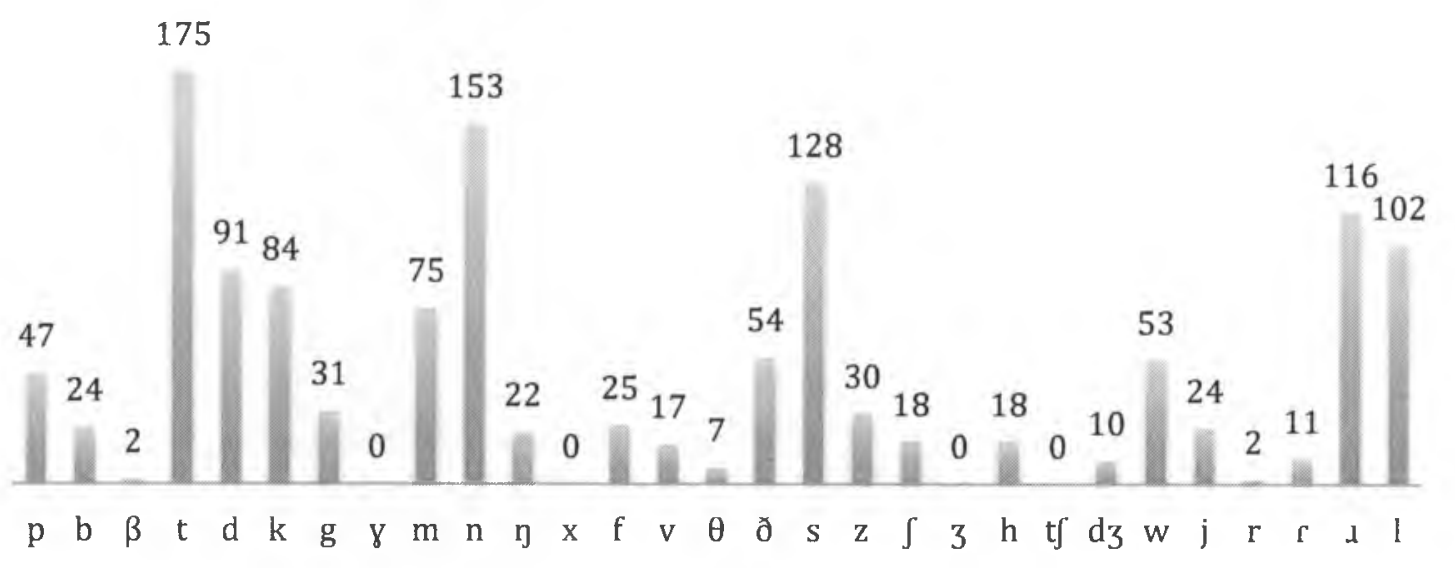

Table 4. Number of Attempts of Speech Sounds

In addition, the level of complexity of English speech sounds was consistent with level E of Dinnsen et al.'s (1990) study. The child's phonetic inventory included strident sound distinction (e.g., /s/ and / $/ \theta /$ ) and lateral sound distinction (e.g., /s/ and /l/), both indicators of the highest levels of phonetic complexity in English. Level A was accomplished with the production of / $\mathrm{pt} \mathrm{k} \mathrm{m} \mathrm{n} \mathrm{jw}$ /. These sounds were categorized based on consonantal, sonorant, and coronal features. Level B was accomplished with the productions of / b d g/ based on voiced and anterior features. Level C was accomplished with the production of / $\mathrm{f} v \theta \delta \mathrm{s} z \int \mathrm{d} z \mathrm{~h} /$ based on continuant and delayed release features. Level D was accomplished with the production of / I and $\mathrm{l}$ based on nasal features, or distinctions between nasal and liquid sounds. 
The Spanish inventory was limited based on the length of sentences and amount of verbal output. However, the level of complexity of Spanish speech sounds was consistent with level D of Catano et al.'s (2009) study. The child's phonetic inventory included at least one $(/ \mathrm{r} /)$ of the two $(/ \mathrm{r} /$ or $/ \mathrm{r} /)$ phonemes that distinguish level $\mathrm{D}$. Level A was accomplished with the production of / $\mathrm{pt} \mathrm{k} \mathrm{m} \mathrm{n} \mathrm{j} 1 \mathrm{wj} /$ phonemes based on sonorant, coronal, and nasal features. Level B was accomplished with the production of / b $\beta$ / phonemes based on voicing features; although the child of this study did not show production of voiced, anterior sounds in Spanish like/g/, she was awarded the level B complexity as her complete phonological inventory included the sound. Level C was accomplished with the production of / $\mathrm{s}$ $\int /$ phonemes based on lateral or strident features. The phonological inventory of the child in this study did not qualify as level E, as this requires the presence of all three $/ 1 /, / \mathrm{r} /$, and $/ \mathrm{r} /$ phonemes. The child had multiple opportunities to produce the trill /r/ sound, but the sound was realized as the $/ 1 /$ phoneme. Figure 8 demonstrates the English and Spanish phonological complexities. 


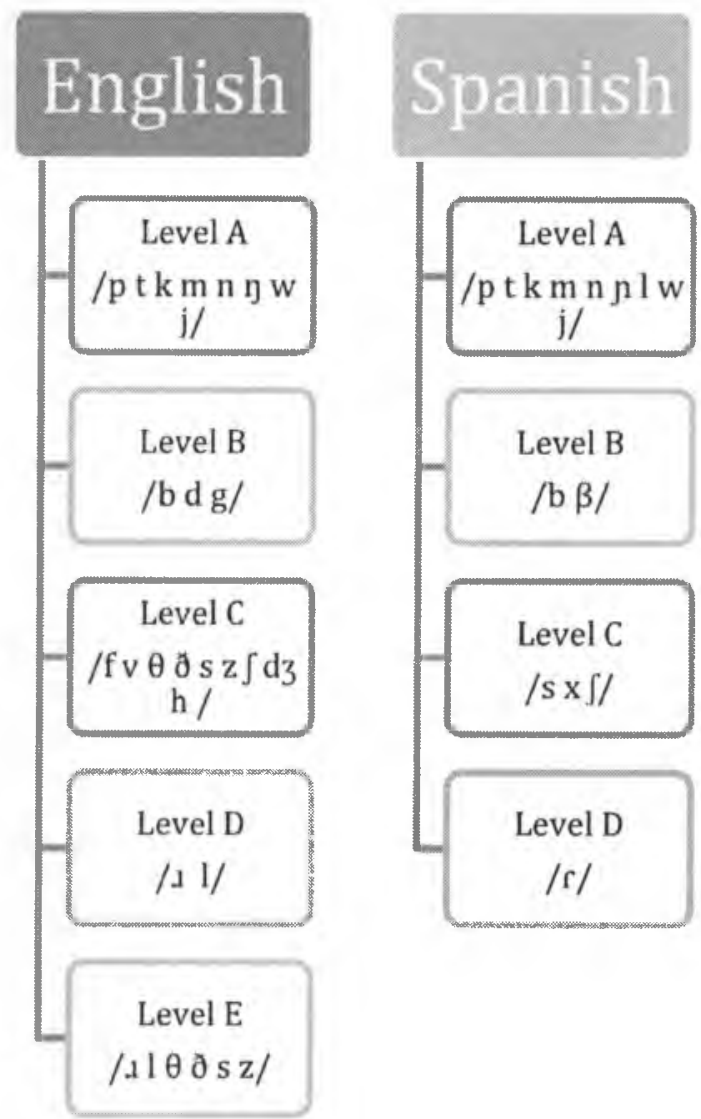

Figure 8. Hierarchy of Phonological Levels of Complexity

Furthermore, the participant of this study had a phonological inventory that closely matched the inventories and complexity of her bilingual Spanish-Englishspeaking and peers in Fabiano-Smith and Barlow's (2010) study of bilingual speech sound classes (Figure 9). The children of Fabiano-Smith and Barlow's (2010) study had English phonological inventories that were categorized as Level E, with the exception of 2 of the 8 children who had inventories categorized as Level D. The children also had 
Spanish phonological inventories that were categorized as Level D, with the exception of 1 of the 8 children who had an inventory categorized as Level C.

Bilingual children's phonetic inventories for Spanish and English

\begin{tabular}{|c|c|c|c|c|}
\hline Child ID & Spanish & Level & English & Level \\
\hline BOI & $p b t k g s \times \beta O$ y $m f y$ & $\mathrm{D}$ & 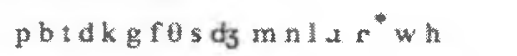 & $\mathrm{E}$ \\
\hline $\mathrm{BO2}$ & $p b t k g j m n f s \times l r$ & $\mathbf{D}$ & 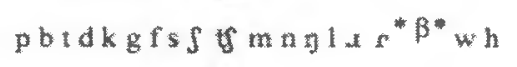 & $\mathbf{E}$ \\
\hline Bo3 & pbtdkgsfmarj & $\mathrm{D}$ & $p b r d k g f s t f m n l a$ & $\mathrm{D}$ \\
\hline BO4 & $p b t d k g f s x m \mid r j$ & $\mathrm{D}$ & pbldkgfsmnliwh & $\mathrm{D}$ \\
\hline Bos & pbtdkgfsxymaj & $\mathbf{D}$ & pbldkgfszmnta $r^{*} w h$ & E \\
\hline $\mathrm{B} 06$ & $p b t d k g f s \beta \gamma m n l r j$ & $\mathrm{D}$ & 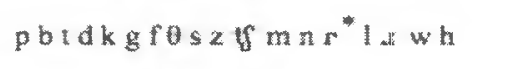 & $\mathbf{E}$ \\
\hline 807 & $p b t d k g f s \times \beta y m n l j w$ & c & pbtdkgfsznl $x$ wh & E \\
\hline Bo8 & pbrkgrsxz*Boymalrj & $\mathrm{D}$ & pbtakgfs tom $n+x^{*}$ wh & $\mathrm{E}$ \\
\hline
\end{tabular}

Instances of transfer

Figure 9. from Fabiano-Smith and Barlow's (2010) Bilingual Children's Phonetic Inventories for Spanish and English

\section{Discussion}

The purpose of this current study was to evaluate the speech sound production of a Spanish-English bilingual child, in spontaneous speech, and to compare the phonetic inventories and levels of complexity to her monolingual English- and Spanish-speaking peers. 
The phonological inventory of the child of this study closely matches that of her monolingual English-speaking peers when compared to customary ages of production. This would suggest that spontaneous speech samples could provide information that is consistent with traditional elicitation tasks in determining customary age of master of speech sounds.

The subject produced all age-appropriate English speech sounds with high accuracy as outlined by Sander (1972). The participant had much difficulty in the production of $/ \delta /$ and $/ \mathbf{x} /$ phonemes, although they were in her phonological inventory. These two sounds are late developing sounds, and it would be expected for children her age to make similar errors (i.e., $\partial \rightarrow d,\rfloor \rightarrow w$ ). The child in this study, however, had a higher accuracy of liquid /1/ production that would be unexpected in her monolingual peers.

Smit (1993) conducted a study on the common error types made by children in the Iowa-Nebraska Articulation Norms Project. They tested over 900 children ranging in age from 2 to 9 years old. The children 5 years of age and under frequently, between $20 \%$ and $65 \%$, substituted liquid sounds with the glide phoneme $/ \mathrm{w} /$. Yet, the child in this current study had close to $100 \%$ accuracy in production of the /// phoneme with only one instance of spontaneous speech when she substitutes /w/ for $/ 1 /$. One explanation for this high accuracy can possibly be attributed to the early customary production of the /1/ phoneme in the Spanish language. Jimenez (1987) highlights that the /1/ phoneme in Spanish is an early developing sounds with children typically acquire above $90 \%$ 
accuracy before the age of 4 years old. This can partly be due to the high frequency of Spanish words that utilize the /// phoneme (e.g., articles la, las, el and los, direct object pronouns $l o, l o s, l a$, and $l a s$, indirect object pronouns $l e$ and $l e$, etc.). While this would not be considered transfer between languages as both English and Spanish languages have the $/ 1 /$ phoneme in their inventories, this may be an example of how one language accelerates production in another, as opposed to deceleration (Paradis and Genesee, 1996).

The expressive Spanish inventory of this current child did not include trill $/ \mathrm{r} /$ sound class, although this is expected in monolingual Spanish-speaking children of a similar age. As the two sounds $/ \mathrm{r} /$ and $/ \mathrm{r} /$ are developmentally late sounds, as outlined by Jimenez (1987), the current child did not have accurate production $/ \mathrm{r} /$ or high accurate production $/ \mathrm{s} /$ regardless of word position or frequency of appearance. Instead, one error pattern observed was the substitution of $/ \mathrm{l} /$ for both $/ \mathrm{r} /$, and $/ \mathrm{r} /$. The substitution may be attributed to similar places of articulation (i.e., tip of the tongue to the alveolar ridge), but differing manners. The /l/ phoneme requires the constant contact of the tip of the tongue to the alveolar ridge as air is passed laterally in the oral cavity. The constant contact may be more easily accomplished than the single tap of the tip of the tongue to the alveolar ridge in production of the / $/$ phoneme or the repetitious trilling of the tip of the tongue to the alveolar ridge in the production of the $/ \mathrm{r} / \mathrm{phoneme}$. This may indicate that liquid, tap, and trill sounds may follow a pattern of simple to complex with /l/ being an early sound that stands as the base for $/ \mathrm{s} /$ and then $/ \mathrm{r} /$ development in bilingual Spanish-English 
speakers. Finally, words containing velar stop /g/ or affricative $/ \mathrm{t} f /$ were not attempted in spontaneous speech in Spanish, although $/ \mathrm{g} / \mathrm{was}$ found in her in English inventory with high accuracy.

As previously mentioned, one of the limitations of analyzing a spontaneous speech sample using customary ages of master is that a child may not attempt every speech sound possible in the target languages. For this reason, assumptions can only be made based on the sounds produced, which may paint an incomplete picture of a child's phonological inventory. Using established phonological levels of complexity, though, the limitations of a spontaneous speech sample might be disregarded. Dinnsen et al.'s (1990) and Catano et al.'s (2009) studies demonstrate levels of complexity may be established by more than one distinction. For example, level D of Spanish complexity may be achieved through the presence of $/ \mathrm{r} /$ or $/ \mathrm{r} /$. The flexibility in requirements lends itself to the very limitations of spontaneous speech sampling. This could be beneficial to the assessment of speech language disorders, as observations of a complete phonological inventory would not be necessary to measure the phonological complexity of a child's inventory.

Further analysis was completed on the relation between the spontaneous speech sample of this study's participant and her mother's report of language proficiency and exposure. The inventories and levels of complexity of this current child appear to correlate with the observations of Pearson et al. (1997) on language input and language production. They found specifically that the amount of exposure to target languages for 
bilingual children corresponded to vocabulary development and recommended thresholds for participation in bilingual language research. The participant of this study met the thresholds recommended for participation in bilingual research by exceeding the $20 \%$ target language input level (i.e. she was described to have a 63:37 percent ratio of input in both target languages), and there is a clear correlation between phonological inventory complexity and hours per week of language input. The exposures to English and Spanish are not equally distributed throughout the week, with the majority of activities being conducted in English. This corresponds to the results of the current study, where the participant has levels E and D for her English and Spanish inventories, respectively. This finding could support the use of spontaneous speech sampling in assessing bilingual language ability. It could indicate that the complexity of a recorded speech sample should match to the reported levels of language exposure. If, for example, a child has a high level of language exposure, but a low level of speech complexity for her age, then further investigation of some disorder (e.g., full phonetic inventory stimulation tasks) may be warranted.

This study is additionally supported by Restrepo (1998) and Gutierrez-Clellen and Kreiter (2003) works on scaled scores and parent report in accuracy of predicting bilingualism. Paul and Jennings (1992) conducted a study on expressive language abilities and their relation to complexity of syllabic structure, number of consonant in phonemic inventories, and percentage of consonants correctly produce. They recruited 28 children who were slow to develop expressive language, and 25 typically developing 
children, to complete language tasks. The findings of their study support a positive relationship between phonological inventory and expressive language as the children who had more complex inventories had higher percentages of consonant accuracy and higher expressive language abilities. English language skills were reported to be consistent with Pena et al.'s (2003) proficiency rating of 4, the highest level, and Spanish language skills consistent with a proficiency rating of 3 , the second highest level. This would suggest that spontaneous speech sampling has some validity when compared to parent report of language proficiency and analyzed by language phonological complexity.

\section{Conclusion}

Normative data on bilingual language development is sparse, although there is a growing field of research dedicated to collecting this data. With the expansion of the research surrounding bilingual language development, clinicians may feel more confident in their interactions with children of diverse backgrounds and may provide more reliable assessments, diagnosis, and interventions. This study set out to determine the relevancy of information attained from the gathering of data via a spontaneous speech sample and its analysis in through traditional and emerging methods. At the very least, it would appear that spontaneous speech samples provide information consistent with elicited speech samples. 
When analyzing spontaneous speech samples using ages of customary production, the data of this study is comparable to that of previous studies using elicitation tasks. Of course, without full production or attempt at full production of all speech sounds within a target language, spontaneous speech paints an incomplete picture of a full phonological inventory - at least when analyzing each phoneme individually. Though, the spontaneous speech sample of this study did provided information regarding the frequency of attempts of specific speech sounds in typical conversations. This information could be beneficial to the production of future assessments for bilingual Spanish-English children. If elicited speech tasks are to measure the true abilities of a child, this information serves a purpose in eliciting the most common sounds. A thorough investigation of the frequency of speech sound combinations in bilingual children would be the next step in gathering data relevant to bilingual speakers' speech production.

When analyzing the spontaneous speech sample of the current child using phonological levels of complexity, the limitations of gathering data in such a manner become less restrictive. This study demonstrates that spontaneous speech sampling could provide information that is just as adequate as elicited speech tasks, though more representative of authentic speech sound production. More research would be needed in order to prove how reliable spontaneous speech tasks are in predicting levels of complexity.

This study was not completed without limitations. One limitation of this study is the analysis of speech sounds using levels of complexity. In Dinnsen et al. (1990) and 
Catano et al. (2009), phonological levels of complexity were established with the production a phoneme at least twice during the given tasks. This was accomplished as the children were prompted more than once to produce each sound of the English and Spanish languages. The child of this current study was not prompted to produce sounds nor did she produce some sounds more than once, although all sounds produced at least once were said to exist in her phonological inventories. While it is not guaranteed to observe the production of each speech sound, let alone twice, using spontaneous speech sampling, future research should investigate the validity in creating phonological inventories using speech sounds observed just once versus speech sounds observed multiple times. Another limitation of this study is that the research was based on a single subject. It would be difficult to generalize the data obtain through this project to other children based on multiple factors, such as language dyads, dialects, language exposure, and disorders. Also, the data obtained is based on a single snapshot in time. Thought the language sample was obtained over several days, a more thorough investigation of spontaneous speech sampling would take place over a longer period of time with a more diverse group of typical conversation partners. The final limitation of this study is the clinical relevance of analyzing spontaneous speech samples using levels of phonological complexity. Dinnsen et al. (1990) and Catano et al. (2009) did not create their level systems with ages of mastery in consideration. For this reason, it can only be interpreted that levels of phonological complexity only apply to children up to the age of 5 years old. Additionally, there are no specific age measures as to which level of complexity 
corresponds to which ages. Future research would address the correlation between levels of complexity to some age marker for clinical interpretations. 


\section{References}

Azevedo, M. (2009). Introducción a la lingüística española (3rd ed.). Upper Saddle River, NJ: Prentice Hall.

Bedore, L. M., \& Pena, E. D. (2008). Assessment of bilingual children for identification of language impairment: Current findings and implications for practice. International Journal of Bilingual Education and Bilingualism, 11(1), 1-29.

Bunta, F., \& Ingram, D. (2007). The acquisition of speech rhythm by bilingual Spanishand English-speaking 4- and 5-year-old children. Journal Of Speech, Language \& Hearing Research, 50(4), 999-1014.

Casey, B. J., Giedd, J. N., \& Thomas, K. M. (2000). Structural and functional brain development and its relation to cognitive development. Biological Psychology, $54(1-3), 241-257$.

Cataño, L., Barlow, J. A., \& Moyna, M. I. (2009). A retrospective study of phonetic inventory complexity in acquisition of Spanish: Implications for phonological universals. Clinical Linguistics \& Phonetics, 23(6), 446-472.

Chang, C. B. (2008). Variation in palatal production in Buenos Aires Spanish. UC Berkeley Phonology Annual Report. 
Dinnsen, D. A., Chin, S. B., Elbert, M., \& Powell, T. W. (1990). Some constraints on functionally disordered phonologies: Phonetic inventories and phonotactics. Journal of Speech, Language, and Hearing Research, 33(1), 28-37.

Edwards, H. T. (2003). Applied phonetics: the sounds of American English. San Diego: Singular Publishing Group, Inc.

Edwards, J., \& Beckman, M. E. (2008). Methodological questions in studying consonant acquisition. Clinical Linguistics \& Phonetics, 22(12), 937-956.

English Phonemic Inverntory. (n.d.). Retrieved November 4, 2015, from http://www.asha.org/uploadedFiles/practice/multicultural/EnglishPhonemicInvento ry.pdf

Fabiano-Smith, L., \& Barlow, J. A. (2010). Interaction in bilingual phonological acquisition: Evidence from phonetic inventories. International Journal of Bilingual Education and Bilingualism, 13(1), 81-97.

Fabiano-Smith, L., \& Goldstein, B. A. (2010). Phonological acquisition in bilingual Spanish-English speaking children. Journal of Speech, Language, and Hearing Research, 53(1), 160-178.

Gathercole, V. C. M., \& Hoff, E. (2007). Input and the acquisition of language: Three questions. Blackwell handbook of language development, 107-127. 
Genesee, F. (1989). Early bilingual development: one language or two?. Journal of Child Language, 16(1), 161-179.

Genesee, F., Paradis, J., \& Crago, M. B. (2004). Dual language development \& disorders: A handbook on bilingualism \& second language learning, vol 11. Paul H Brookes Publishing.

Gildersleeve-Neumann, C. E., \& Wright, K. L. (2010). English speech acquisition in 3-to 5-year-old children learning Russian and English. Language, Speech, and Hearing Services in Schools, 41(4), 429-444.

Girbau, D., \& Schwartz, R. G. (2008). Phonological working memory in Spanish-English bilingual children with and without specific language impairment. Journal of Communication Disorders, 4I(2), 124-145.

Goldman, R., \& Goldman, F. M. (2000). Fristoe Test of Articulation. American Guidance Service.

Goldstein, B., \& Cintrón, P. (2001). An investigation of phonological skills in Puerto Rican Spanish-speaking 2-year-olds. Clinical Linguistics \& Phonetics, 15(5), 343361.

Goldstein, B. A., Fabiano, L., \& Washington, P. S. (2005). Phonological skills in predominantly English-speaking, predominantly Spanish-speaking, and Spanish- 
English bilingual children. Language, Speech, and Hearing Services in Schools, $36(3), 201-218$

Goldstein, B., \& Washington, P. S. (2001). An initial investigation of phonological patterns in typically developing 4-year-old Spanish-English bilingual children. Language, Speech, and Hearing Services in Schools, 32(3), 153-164.

Grosjean, F. (1994). Individual bilingualism. In R. E. Asher (Ed.), The encyclopaedia of language and linguistics (pp. 1656-1660). Oxford, UK: Pergamon Press.

Guitart, J. M. (1997). Variability, multilectalism, and the organization of phonology in Caribbean Spanish dialects. F. Martinez-Gil \& A. Morales-Front (Eds.), Issues in the phonology and morphology of the major Iberian languages, 515-536.

Gutierrez-Clellen, V. F., \& Kreiter, J. (2003). Understanding child cilingual acquisition using parent and teacher reports. Applied Psycholinguistics, 24(2), 267-88.

Holm, A., \& Dodd, B. (1999). A longitudinal study of the phonological development of two Cantonese-English bilingual children. Applied Psycholinguistics, 20(3), 349376.

Humes, K., Jones, N. A., \& Ramirez, R. R. (2011). Overview of race and Hispanic origin, 2010. US Department of Commerce, Economics and Statistics Administration, US Census Bureau. 
Hurford, J. R. (1991). The evolution of the critical period for language acquisition. Cognition, 40(3), 159-201.

Jimenez, B. C. (1987). Acquisition of Spanish consonants in children aged 3-5 years, 7 months. Language, Speech, and Hearing Services in Schools, 18(4), 357-363.

Kemp, C. (2009). Defining multilingualism. The Exploration of Multilingualism: Development of research on L3, multilingualism and multiple language acquisition, 6,11 .

Keshavarz, M. H., \& Ingram, D. (2002). The early phonological development of a FarsiEnglish bilingual child. International Journal of Bilingualism, 6(3), 255-269.

Kimble, C. (2013). Speech-language pathologists' comfort levels in English language learner service delivery. Communication Disorders Quarterly.

Klein, H. B., \& Altman, E. K. (2002). The acquisition of medial/t, d/allophones in bisyllabic contexts. Clinical Linguistics \& Phonetics, 16(3), 215-232.

Kritikos, E. P. (2003). Speech-language pathologists' beliefs about language assessment of bilingual/bicultural individuals. American Journal of Speech-Language Pathology, 12(1), 73-91.

Lidz, C. S., \& Pena, E. D. (1996). Dynamic assessment: The model, its relevance as a nonbiased approach, and its application to Latino American preschool children. Language, Speech, and Hearing Services in Schools, 27(4), 367-372. 
Lord, G. (2005). (How) Can we teach foreign language pronunciation? On the effects of a Spanish phonetics course. Hispania, 557-567.

Paradis, J., \& Genesee, F. (1996). Syntactic acquisition in bilingual children. Studies in Second Language Acquisition, 18(1), 1-25.

Paul, R., \& Jennings, P. (1992). Phonological behavior in toddlers with slow expressive language development. Journal of Speech, Language, and Hearing Research, 35(1), 99-107.

Pearson, B. Z., Fernandez, S. C., Lewedeg, V., \& Oller, D. K. (1997). The relation of input factors to lexical learning by bilingual infants. Applied Psycholinguistics, $18(1), 41-58$.

Pena, E., Bedore, L. M., \& Rappazzo, C. (2003). Comparison of Spanish, English, and bilingual children's performance across semantic tasks. Language, Speech, and Hearing Services in Schools, 34(1), 5-16.

Pieretti, R. A., \& Roseberry-McKibbin, C. (2015). Assessment and intervention for English language learners with primary language impairment research-based best practices. Communication Disorders Quarterly.

Place, S., \& Hoff, E. (2011). Properties of dual language exposure that influence 2-year-olds' bilingual proficiency. Child development, 82(6), 1834-1849. 
Poole, I. (1934). Genetic development of articulation of consonant sounds in speech. The Elementary English Review, 159-161.

Poole-Davis, I. (1938). The speech aspects of reading readiness. Newer Practices in Reading in the Elementary School, 282-89.

Prather, E. M., Hedrick, D. L., \& Kern, C. A. (1975). Articulation development in children aged two to four years. Journal of Speech and Hearing Disorders, 40(2), 179-191.

Pujol, J., Reixach, J., Harrison, B. J., Timoneda-Gallart, C., Vilanova, J. C., \& PérezAlvarez, F. (2008). Posterior cingulate activation during moral dilemma in adolescents. Human Brain Mapping, 29(8), 910-921.

Restrepo, M. A. (1998). Identifiers of predominantly Spanish-speaking children with language impairment. Journal of Speech, Language, and Hearing Research, $4 I(6), 1398-1411$.

Sander, E. K. (1972). When are speech sounds learned?. Journal of Speech and Hearing Disorders, 37(1), 55-63.

Schiff-Myers, N. B. (1992). Considering arrested language development and language loss in the assessment of second language learners. Language, Speech, and Hearing Services in Schools, 23(1), 28-33. 
Shin, H. B., \& Kominski, R. (2010). Language use in the United States, 2007. US Department of Commerce, Economics and Statistics Administration, US Census Bureau.

Templin, M. C. (1957). Certain language skills in children; their development and interrelationships. University of Minnesota.

Volterra, V., \& Taeschner, T. (1978). The acquisition and development of language by bilingual children. Journal of child language, 5(02), 311-326.

Wellman, B. L., Case, I. M., Mengert, I. G., \& Bradbury, D. E. (1931). Speech sounds of young children. University of Iowa Studies: Child Welfare.

Wheeldon, L., \& Lahiri, A. (1997). Prosodic units in speech production. Journal of Memory and Language, 37(3), 356-381 


\section{Appendix 1 - Language Input Hours}

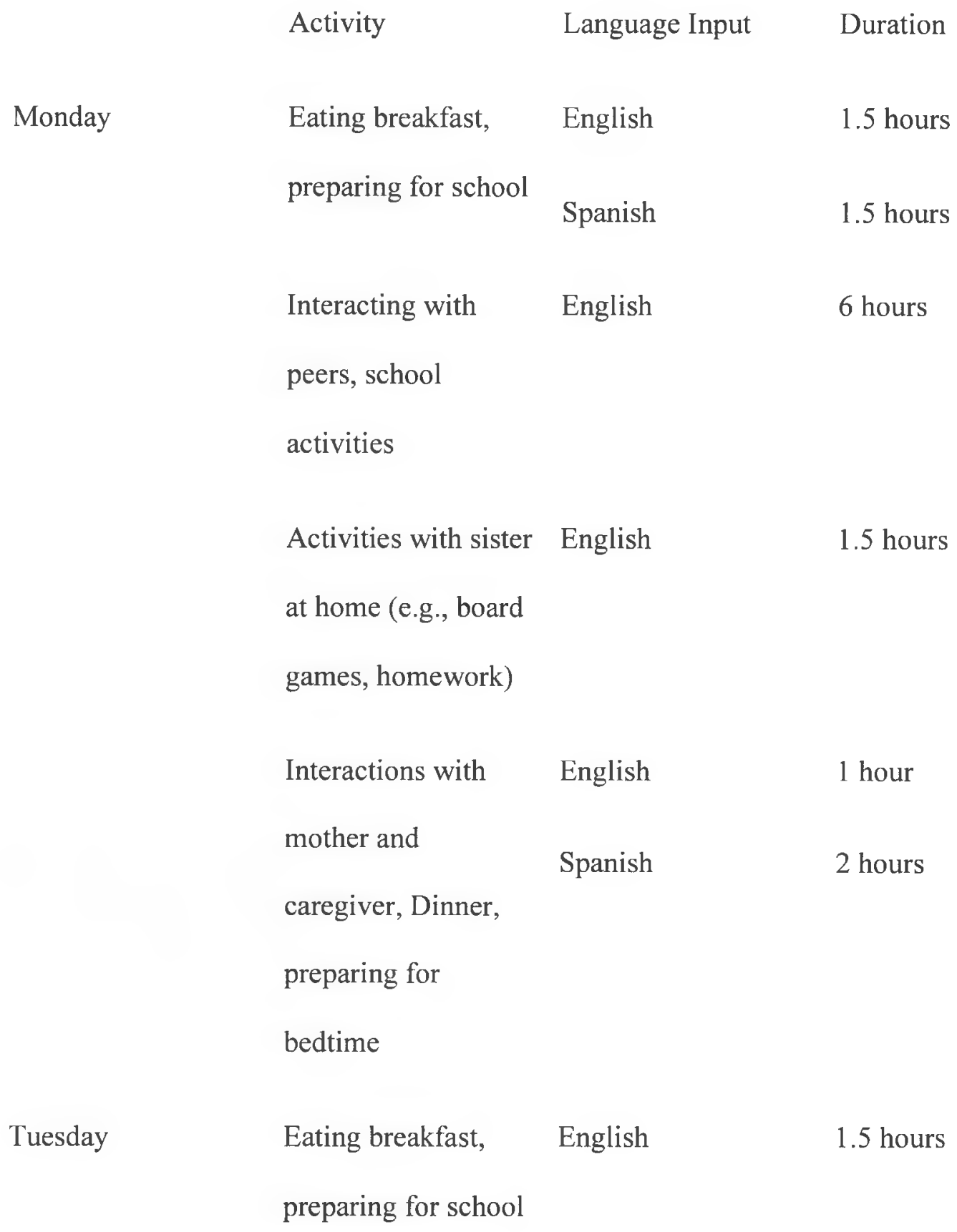


Spanish

1.5 hours

Interacting with

English

6 hours

peers, school

activities

Activities with sister English

1.5 hours

at home (e.g., board

games, homework)

Interactions with

English

1 hour

mother and

Spanish

2 hours

caregiver, Dinner,

preparing for

bedtime

Wednesday

Eating breakfast, English

1.5 hours

preparing for school

Spanish

1.5 hours

Interacting with

English

6 hours

peers, school

activities

Activities with sister English

1.5 hours 


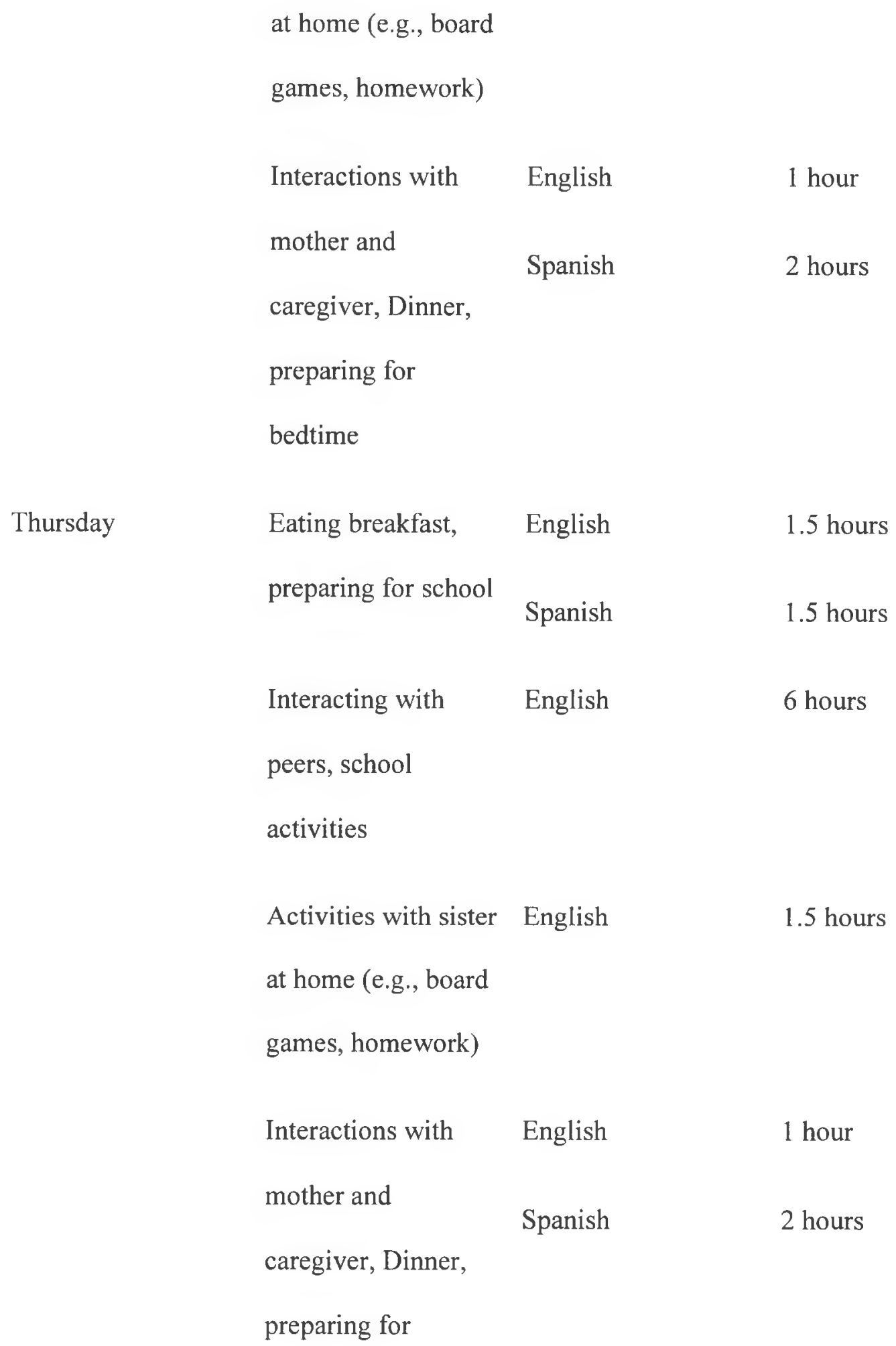


bedtime

Friday

Eating breakfast,
preparing for school

English

1.5 hours

Spanish

1.5 hours

Interacting with

English

6 hours

peers, school

activities

Activities with sister English

1.5 hours

at home (e.g., board

games, homework)

Interactions with

English

1 hour

mother and

Spanish

2 hours

caregiver, Dinner,

preparing for

bedtime

Saturday/Sunday

Breakfast time,

English

1.5 hours

beginning of the day

Spanish

1.5 hours

interactions 


$\begin{array}{llr}\text { Interactions with } & \text { English } & 6 \text { hours } \\ \text { community (e.g., } & & \\ \text { park, shopping) } & & \\ \text { Interactions in } & \text { English } & \\ \text { temple } & & \\ \text { Interactions with } & \text { English } & 3 \text { hours } \\ \text { mother and } & \text { Spanish } & 4 \text { hours } \\ \text { caregiver, Dinner, } & \\ \text { preparing for } & \\ \text { bedtime } & \\ \text { Leisure time } & \text { English } & \\ \text { activities (e.g., play, } & \text { Spanish } & \\ \text { reading, movies) } & \\ \text { with mother and } & & \\ \text { sister } & & \\ \end{array}$

